\title{
A EXPANSÃO DA PÓS-GRADUAÇÃO EM DIREITO NO BRASIL (1998- 2017): AVANÇO QUANTITATIVO E PERSISTÊNCIAS METODOLÓGICAS
}

THE EXPANSION OF POSTGRADUATE STUDIES IN LAW IN BRAZIL (19982017): QUANTITATIVE PROGRESS AND METHODOLOGICAL PERSISTENCE

LA EXPANSIÓN DE LOS ESTUDIOS DE POSGRADO EN DERECHO EN BRASIL (1998-2017): PROGRESO CUANTITATIVO Y PERSISTENCIA METODOLÓGICA

\author{
DÉCIO VIEIRA DA ROCHA \\ http://orcid.org/0000-0003-2889-7377 / http://lattes.cnpq.br/4952801804508516 / deciovrocha@hotmail.com \\ Faculdade Getúlio Vargas (FGV) \\ Rio de Janeiro, RJ, Brasil \\ FERNANDO LEAL \\ http://orcid.org/0000-0001-9004-5904 / http://lattes.cnpq.br/9858226603548264 / fernando.leal@fgv.br \\ Faculdade Getúlio Vargas (FGV) \\ Rio de Janeiro, RJ, Brasil \\ LEANDRO MOLHANO RIBEIRO \\ http://orcid.org/0000-0002-0827-6103 / http://lattes.cnpq.br/9288460281852924 / leandro.ribeiro@fgv.br \\ Faculdade Getúlio Vargas (FGV) \\ Rio de Janeiro, RJ, Brasil
}

\begin{abstract}
RESUMO
O objetivo do artigo é descrever aspectos quantitativos e qualitativos da expansão dos programas de pós-graduação stricto sensu em Direito nas últimas duas décadas (1998-2017). Para isso construímos um banco de dados original com dados públicos dos programas da área contidos na plataforma Sucupira e no GeoCAPES. A análise dos dados revela que a área do Direito teve um crescimento substantivo tanto do ponto de vista quantitativo (expansão no número de discentes, docente, cursos e publicações) quanto qualitativo (formação de quadros de pesquisadores metodologicamente orientados). Além disso, o movimento de expansão foi acompanhado de uma diversificação temática de estudos, configurando programas cada vez mais multidisciplinares. Em grande medida, tal crescimento está associado a incentivos proporcionados pela atividade regulatória da Capes. Porém, aparentemente, esse aumento não veio acompanhado de um maior rigor nos métodos de análise (quantitativos ou qualitativos) para 0 desenvolvimento de pesquisas na área do Direito, o que pode explicar a pouca reprodutibilidade e pouco impacto das pesquisas elaboradas na área.
\end{abstract}

Palavras-chave: Evolução da pesquisa em Direito; metodologia de pesquisa em direito; regulação da CAPES.

\section{ABSTRACT}

The aim of the article is to describe quantitative and qualitative aspects of the expansion of stricto sensu graduate programs in law in the last two decades (1998-2017). For this, we built an original database with public data of the programs in the area contained in the Sucupira platform and GeoCAPES. The analysis of the data reveals that the area of Law had a substantial growth both from the quantitative point of view (expansion in the number of students, teachers, courses and publications) and qualitative (formation of staff of methodologically oriented researchers). In addition, the expansion movement was accompanied by a thematic diversification of studies, configuring increasingly multidisciplinary programs. To a large extent, such growth is associated with incentives provided by Capes' regulatory activity. However, apparently, this increase was not accompanied by greater rigor in the methods of analysis 
(quantitative or qualitative) for the development of research in the field of Law, which may explain the low reproducibility and little impact of the research carried out in the area.

Keywords: CAPES regulation; evolution of legal research; methodology of legal research.

\section{RESUMEN}

El propósito del artículo es describir los aspectos cuantitativos y cualitativos de la expansión de los dos programas de posgrado stricto sensu en Derecho en las dos últimas décadas (1998 - 2017). Para eso, se construyó una base de datos públicos de los programas de área existentes en la plataforma Sucupira y en GeoCAPES. Un análisis de los datos revela un área de dirección directa de crecimiento sustancial tanto desde el punto de vista cuantitativo (expansión del número de estudiantes, profesores, cursos y publicaciones) como del cualitativo (formación de cuadros de investigadores metodologicamente orientados). Aún, el movimiento de expansión para una compañía de diversificación temática de estudios, configuración de programas más multidisciplinares. En gran parte, el crecimiento se asoció a incentivos proporcionados por la autoridade reguladora de CAPES. Por ejemplo, aparentemente, el aumento no fue seguido por un mayor rigor en los métodos de análisis (cuantitativos o cualitativos) para el desarrollo de la investigación en el área del Derecho, lo que puede explicar la baja reproductibilidad y el escaso impacto de las investigaciones realizadas en la temática.

Palabras clave: Evolución de la investigación en derecho; metodología de la investigación en derecho; regulación CAPES.

\section{SUMÁRIO}

INTRODUÇAO; 1 A INDISTINÇÃO ENTRE PRÁTICA PROFISSIONAL E ATIVIDADE ACADÊMICA: O DESAFIO DA PÓS-GRADUAÇÃO EM DIREITO NO BRASIL, 2 DADOS E A BUSCA POR ALTERNATIVAS REGULATÓRIAS, 3 EXPANSÃO E INSTITUCIONALIZAÇÃO DOS PROGRAMAS DE PÓS-GRADUAÇÃO EM DIREITO NO BRASIL, 4 PRODUÇÃO E IMPACTO; CONCLUSÃO; REFERÊNCIAS; ANEXO.

\section{INTRODUÇÃO}

Nas duas últimas décadas houve uma expansão considerável dos cursos de Ensino Superior no Brasil ${ }^{1}$. O mesmo se deu com a pós-graduação stricto sensu. Diante disso, questiona-se em que medida a expansão observada nos programas de mestrado e doutorado nas últimas décadas propiciou a institucionalização da pesquisa acadêmica na área do Direito? Embora o ensino de Direito seja um dos mais tradicionais no $B$ rasil ${ }^{2}$, o sistema de pós-graduação até fins da década de 1980 contava com apenas 14 cursos dessa natureza na área ${ }^{3}$, fato comumente associado à percepção do Direito como um espaço marcado pela pouca diferenciação entre aplicadores (ou operadores do direito) e acadêmicos. Nesse contexto, e reproduzindo a relação tradicional entre

\footnotetext{
1 BRASIL. Instituto Nacional de Estudos e Pesquisas Educacionais Anísio Teixeira (Inep). Censo da Educação Superior 2018: notas estatísticas. Brasília, 2019. Disponível em: https://download.inep.gov.br/educacao_superior/censo_superior/documentos/2019/censo_da_educacao_ superior_2018-notas_estatisticas.pdf . Acesso em: 30 abr. 2020.

2 MARTINS, Carlos Benedito; CARVALHO, Inaiá Maria Moreira de. Mestres e doutores em Direito. In: VELLOSO, Jacques (org.). A pós-graduação no Brasil: formação e trabalho de mestres e doutores no país (volume 2). Brasília: Capes, 2003

${ }^{3}$ Majoritariamente cursos de mestrado.
} 
academia e militância profissional, os poucos programas existentes estavam voltados a formar mestres e doutores em temas tradicionalmente dogmáticos, reconduzíveis a "grandes áreas" e "ramos tradicionais" do direito, como Direito Constitucional, Direito Civil, Direito Público e Direito Privado. Tais cursos estavam concentrados majoritariamente em instituições públicas de ensino superior.

Com a expansão dos programas de pós-graduação stricto sensu em Direito (PPGD) iniciada já na década de 1990, com destaque para as alterações pelas quais o sistema regulatório coordenado pela Coordenação de Aperfeiçoamento de Pessoal de Nível Superior (CAPES) passou em 1998 e que o caracterizam até hoje ${ }^{4}$, novas frentes foram abertas. As áreas de concentração foram ampliadas para também englobarem temáticas como Direito Ambiental, Direito Agrário, Direito e Tecnologia, entre outros diversos temas, embora os programas “clássicos" de Direito ainda fossem dominantes ${ }^{5}$. Esse movimento de expansão pode ser considerado um efeito direto de políticas voltadas a incentivar o desenvolvimento de programas em setores cada vez mais específicos do conhecimento e das exigências de diferenciação das propostas de novos entrantes, já na apresentação de proposta de curso novo, dos demais programas existentes, especialmente no âmbito regional ${ }^{6}$. Além disso, contribuem para essa nova realidade fatores como a maior institucionalização e profissionalização de práticas acadêmicas na área que, como será visto, foram obtidos pela incorporação de professores permanentes e de dedicação exclusiva nos PPGD.

Para analisar melhor como se deram essas mudanças, busca-se mapear alguns fatores importantes para se captar a institucionalização da área do Direito. Como apontados por Codato e Leite ${ }^{7}$, tais fatores são: a) a evolução do número de programas registrados, b) a evolução no número de discentes matriculados e titulados, c) o surgimento de associações de pesquisa na área do direito e d) o mapeamento dos principais periódicos nacionais e internacionais. Incorporamos a esses fatores o perfil dos docentes dos PPGD. Esses fatores nos dão uma visão

\footnotetext{
${ }^{4}$ DOTTA, Alexandre Godoy. A estrutura e o financiamento da pós-graduação no Brasil no contexto do desenvolvimento do serviço público de educação. Administrativo \& Constitucional, Belo Horizonte, v. 14, n. 56, $\quad$ p. 229-245, 2014. Disponível http://www.revistaaec.com/index.php/revistaaec/article/view/100 . Acesso em: 30 abr. 2020.

${ }^{5}$ Essa diversificação das áreas de concentração dos programas de pós-graduação stricto sensu em direito pode ser observada no quadro do Anexo 1.

${ }^{6}$ V., por exemplo, https://www.capes.gov.br/images/Criterios_apen_2019/DIREITO.pdf, p. 4 e 5.

${ }^{7}$ CODATO, Adriano; LEITE, Fernando. Autonomização e institucionalização da ciência política brasileira: o papel do sistema Qualis-Capes. Agenda Política, [s.l], v.1, n.1, p. 1-21, 2013. Disponível em: https://www.agendapolitica.ufscar.br/index.php/agendapolitica/article/view/10 . Acesso em: $30 \mathrm{abr}$. 2020.
} 
abrangente de como a área tem se conformado e em que sentido tem caminhado ao longo do tempo.

Para dar conta desses objetivos construiu-se uma base de dados original, com os dados públicos existentes na plataforma sucupira e no sistema GeoCAPES. As análises vão de 1998 a 2017 e esse recorte temporal se deu essencialmente pela disponibilidade de dados públicos da CAPES. Embora o debate sobre a institucionalização da área do Direito e seus aspectos já encontre diversos interlocutores ${ }^{8}$, o presente trabalho se destaca pela pretensão de compilar dados de todos os programas existentes com dados públicos e descrever sua evolução, a partir dos fatores enumerados acima.

Este artigo conta, para além desta introdução, com uma análise da formação do sistema de pós-graduação e pesquisas na área do Direito. Na segunda seção faz-se uma análise do impacto regulatório que a CAPES exerce sobre esse processo de institucionalização da área e sua importância para o atingimento desse e outros objetivos que orientam a sua atividade como órgão regulador da educação superior no Brasil. Logo após, busca-se construir uma análise descritiva que cobre a expansão dos PPGD desde 1998 até 2017, com o intuito de alinhar uma análise quantitativa das informações existentes com dados qualitativos sobre as mudanças nas temáticas tratadas, acompanhando essa institucionalização na área com a formação de escolas e temas de estudo ligados a novas demandas surgidas. Por fim, faz-se um balanço dos achados com as principais conclusões encontradas no trabalho.

\section{A INDISTINÇÃO ENTRE PRÁTICA PROFISSIONAL E ATIVIDADE ACADÊMICA: O DESAFIO DA PÓS-GRADUAÇÃO EM DIREITO NO BRASIL}

Diferentemente de outras áreas das ciências humanas que foram instituídas especificamente dentro de centros de pesquisa (como as ciências sociais, a história e a geografia, por exemplo ${ }^{9}$ ), o Direito tem como característica central ser um dos primeiros cursos

\footnotetext{
${ }^{8}$ MARTINS, Carlos Benedito; CARVALHO, Inaiá Maria Moreira de. "Mestres e doutores em Direito". In: VELLOSO, Jacques (org.). A pós-graduação no Brasil: formação e trabalho de mestres e doutores no país (volume 2). Brasília: Capes, 2003; NOBRE, Marcos. Apontamentos sobre a pesquisa em direito no Brasil. (2009). Disponível em: https://bibliotecadigital.fgv.br/dspace/handle/10438/2779?show=full. Acesso em: 22 nov. 2019; FRAGALE FILHO, Roberto; VERONESE, Alexandre. A pesquisa em direito: diagnóstico e perspectivas. Revista Brasileira de Pós-Graduação, [s.l], v. 1, n. 2, p. 53-70, nov. 2004. Disponível em: https://rbpg.capes.gov.br/index.php/rbpg/article/view/40 . Acesso em: 30 abr. 2020.; JARDIM, Guilherme Duarte. Mapeamento da produção de pesquisa em Direito no Brasil (2003-2012). Trabalho submetido ao IV Encontro de Pesquisa Empírica em Direito. Ribeirão Preto. 2014.

${ }^{9}$ A este respeito ver: XAVIER, José Roberto. A Pesquisa Empírica e o Direito. Rio de Janeiro: Autografia, 2018.
} 
de graduação no Brasil - já no século XIX, ao lado dos cursos de medicina e engenharia - com uma característica de origem comum: o Direito, assim como os outros dois cursos citados, era voltado a formar pessoas para atuarem como profissionais liberais ou para a qualificação dos quadros do Estado ${ }^{10}$. Para Unger, no Brasil e em diversos outros lugares do mundo, "a maior parte dos alunos que cursam direito, sobretudo as faculdades mais prestigiosas, não pretende exercer o direito, em qualquer forma profissional. Destina-se à gestão das empresas, à burocracia e à política"11. Além disso, o fenômeno do bacharelismo como forma de status e distinção social tem sido apontado como uma característica distintiva da área jurídica no Brasil $^{12}$.

A formação bacharelesca e profissionalizante que marcou a origem dos cursos de Direito no país produziu uma quase indistinção entre prática jurídica e pesquisa científica que dominou também o cenário inicial da pós-graduação na área. Essa ausência de diferenciação produziu, na visão de Marcos Nobre ${ }^{13}$, um certo "atraso relativo" da pesquisa em Direito em relação a outras áreas das ciências sociais. Esse atraso teria se dado justamente pela pouca distinção entre o que é prática jurídica e pesquisa na área do Direito, problema que se reflete no modo tradicional - e já tão criticado - de se desenvolver pesquisas jurídicas, marcado por fatores como o discurso ideológico, a advocacia da hipótese, o reverencialismo, o manualismo, o sincretismo e o evolucionismo ${ }^{14}$. Nas palavras de Nobre:

A minha hipótese é que esse atraso está ligado a dois fatores fundamentais. Em primeiro lugar, o isolamento em relação a outras disciplinas das Ciências Humanas e uma peculiar confusão entre a prática profissional e pesquisa acadêmica. É da combinação destes dois fatores que irá resultar uma relação extremamente precária com as disciplinas das Ciências Humanas, como na concepção de o que é o objeto da Ciência do Direito. ${ }^{15}$

\footnotetext{
${ }^{10}$ SCHWARTZMAN. S. 1990. Tradição e Modernidade da Universidade Brasileira. São Paulo, 1990, Mimeo. 11 UNGER, Roberto Mangabeira. Uma nova faculdade de direito no Brasil. Revista de Direito Administrativo, Rio de Janeiro, v. 243, p. 113-131, 2006. Disponível em: https://bibliotecadigital.fgv.br/ojs/index.php/rda/article/view/42553 . Acesso em: 3 dez. 2021.

12 LEAL, Victor Nunes. Coronelismo, Enxada e Voto. Rio de Janeiro, Forense, 1948.

; HOLANDA, Sérgio Buarque de. Raízes do Brasil. (26a edição) São Paulo: Companhia das Letras, 1995. p. 147.

13 NOBRE, Marcos. Apontamentos sobre a pesquisa em direito no Brasil. (2009). Disponível em: https://bibliotecadigital.fgv.br/dspace/handle/10438/2779?show=full. Acesso em: 22 nov. 2019.

14 OLIVEIRA, L. 2004. Não fale do Código de Hamurabi! A pesquisa sócio-jurídica na pós-graduação em direito. Sua excelência o comissário e outros ensaios de sociologia jurídica. Rio de Janeiro: Letra Legal. Disponivel em: https://edisciplinas.usp.br/pluginfile.php/4213608/mod_resource/content/1/OLIVEIRA\%2C\%20Hamurabi.p df . Acesso em: 3 dez. 2021.

$\frac{15}{15}$ NOBRE, Marcos. Apontamentos sobre a pesquisa em direito no Brasil. (2009). Disponível em: https://bibliotecadigital.fgv.br/dspace/handle/10438/2779?show=full. Acesso em: 22 nov. 2019.
} 
Um efeito prático dessa ausência de um objeto científico do Direito mais claro é que parte considerável das pesquisas empíricas na área eram, desde os anos 80 , conduzidas de modo transversal nos departamentos de Sociologia e Antropologia ${ }^{16}$.

A crítica feita por Nobre teve grande repercussão, mas foi também alvo de objeções. Fragale e Veronese ${ }^{17}$ observam o diagnóstico de Nobre como uma crítica vinda de alguém externo à área que não analisou a especificidade do Direito como área do conhecimento. Os autores revertem o ponto da crítica, sustentando que o "real atraso" na área consistiria na “ausência de uma reflexão epistemológica e metodológica mais consistente", algo que, para eles, "parece ser o grande handicap da área e que necessita ser urgentemente enfrentado"18. Os autores chamam a atenção para a necessidade do Direito se constituir como um espaço mais sólido para alcançar uma melhor inserção no sistema de pós-graduação.

Como se pode notar, embora com críticas distintas, os autores apontam ao mesmo tempo para a necessidade de o Direito se inserir em um modelo mais rigoroso de construção do conhecimento para que possa sustentar seus achados e discussões e alcançar respeitabilidade em outras áreas do saber, algo considerado central para uma área com grande percentual de discentes e docentes na pós-graduação, como será visto mais à frente.

A necessidade de pesquisa que tenha maior impacto, poder de replicação e que não reproduza apenas textos de manuais e ideias já consolidadas contribuiu para o avanço de pesquisas empíricas em Direito. Guilherme Jardim $^{19}$ e José Roberto Xavier ${ }^{20}$ apontam para um crescimento substancial de pesquisas dessa natureza no Direito nos últimos anos. Isso porque a pesquisa passa a buscar uma maior interdisciplinaridade pelo crescimento da área, expandindo os diálogos de pesquisadores do Direito com a produção de pesquisadores, sobretudo das ciências sociais, que antes produziam esparsamente conhecimento sobre problemas jurídicos. Uma das razões enfatizadas por Xavier para essa expansão de pesquisas empíricas como inovação nas

\footnotetext{
${ }^{16}$ XAVIER, José Roberto. A Pesquisa Empírica e o Direito. Rio de Janeiro: Autografia, 2018.

17 FRAGALE FILHO, Roberto; VERONESE, Alexandre. A pesquisa em direito: diagnóstico e perspectivas. Revista Brasileira de Pós-Graduação, [s.l], v. 1, n. 2, p. 53-70, nov. 2004. Disponível em: https://rbpg.capes.gov.br/index.php/rbpg/article/view/40 . Acesso em: 30 abr. 2020.

18 FRAGALE FILHO, Roberto; VERONESE, Alexandre. A pesquisa em direito: diagnóstico e perspectivas. Revista Brasileira de Pós-Graduação, [s.l], v. 1, n. 2, p. 53-70, nov. 2004, p.67. Disponível em: https://rbpg.capes.gov.br/index.php/rbpg/article/view/40 . Acesso em: 30 abr. 2020

19 JARDIM, Guilherme Duarte. Mapeamento da produção de pesquisa em Direito no Brasil (2003-2012). Trabalho submetido ao IV Encontro de Pesquisa Empírica em Direito. Ribeirão Preto. 2014.

${ }^{20}$ XAVIER, José Roberto. A Pesquisa Empírica e o Direito. Rio de Janeiro: Autografia, 2018.
} 
fronteiras do Direito é justamente a grande expansão que a área vivenciou ${ }^{21}$. Entre a década de 1990 e 2017 os cursos de pós-graduação em direito quase quadruplicaram.

Diversos trabalhos utilizam os dados abertos da CAPES para compreender tal expansão. Gameiro e Guimarães ${ }^{22}$ buscaram demonstrar como se estruturaram as redes de relações entre os PPGD apontando para uma desigualdade regional nesta expansão. 0 trabalho de Varela ${ }^{23}$ merece também grande destaque pois como o trabalho apontado anteriormente, demonstra que há pouco intercâmbio na pós-graduação, com parte expressiva dos docentes sendo formados nos

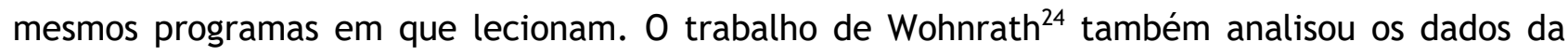
SUCUPIRA e GeoCAPES, mas olhando mais especificamente para a formação de doutores. 0 autor foca sua análise na polarização da formação de doutores em centros de ensino jurídico públicos e confessionais. Por fim, o trabalho de Prado, Santos e Pereira Júnior ${ }^{25}$ analisou os dados quantitativos da CAPES aliados as disciplinas pedagógicas lecionadas em Programas de Direito. Os autores demonstram que ainda é incipiente na formação curricular de mestres e doutores, uma formação pedagógica mais sólida para lidar com a graduação em Direito. Neste trabalho, os achados sobre "persistências epistemológicas e metodológicas" da área se beneficiam desses dados.

O presente trabalho se beneficia destes resultados encontrados em pesquisas anteriores e busca avançar unindo os dados públicos da CAPES com indicadores internacionais de impacto científico para a área do direito. Avança-se, principalmente, em demonstrar que embora a diferenciação entre “operadores do direito" e pesquisadores tenha ocorrido de forma

\footnotetext{
${ }^{21}$ Xavier indica mais dois fatores para a expansão da pesquisa empírica: a) os editais do CNJ, Secretaria de Reforma do Judiciário e Secretaria de Assuntos Legislativos voltados a pesquisadores que tivessem produtos empíricos importantes para esses órgãos. b) organização de pesquisadores empíricos que permitiu maior captação de pesquisadores ligados a metodologia do direito. Essa última razão apontada pelo autor nos parece um efeito direto da expansão da pós-graduação. XAVIER, José Roberto. A Pesquisa Empírica e o Direito. Rio de Janeiro: Autografia, 2018, p.35.

22 GAMEIRO, Ian Pimentel; GUIMARÃES FILHO, Gilberto. O mapa da pós-graduação em Direito no Brasil: uma análise a partir do método da Social Network Analysis. Revista Direito GV, [s.l.], v. 13, n. 3, p. 891 920, jan. 2018. ISSN 2317-6172. Disponível em: http://bibliotecadigital.fgv.br/ojs/index.php/revdireitogv/article/view/73332. Acesso em: 30 Abr. 2020. ${ }^{23}$ VARELLA, Marcelo. Quem influencia a pós-Graduação em Direito no Brasil? Uma análise empírica da nucleação acadêmica. Revista de Direito Brasileira, Florianópolis, v. 12, p. 111-127, 2015. Disponível em: https://www.indexlaw.org/index.php/rdb/article/view/2817/2669 . Acesso em: 3 dez. 2021.

${ }^{24}$ WOHNRATH, Vinicius. Educação e elites jurídicas: espaços de formação doutoral em direito no Brasil contemporâneo. In: DE HOLANDA, Ana Paula A.; GRDILHO, Heron J. de S.; SILVA, Maria dos Remédios F.; MARTINI, Sandra R.; CARDIN, Valéria S. G (Coords.). Filosofia do direito hoje: temas atuais. 1 ed. Zaragoza: Prensas de la Universidad de Zaragoza, 2019, p. 365 - 388.

25 PRADO, E. C.; SANTOS, C. M.; PEREIRA JUNIOR, A. M. Pós-graduação stricto sensu em Direito: onde e como se forma o docente dos cursos de graduação. Revista Brasileira de Pós-Graduação, [s.l], v. 12, p. 443-470, 2015. Disponível em: https://rbpg.capes.gov.br/index.php/rbpg/article/view/814 . Acesso em: 3 dez. 2021.
} 
substantiva, ainda há persistências metodológicas no Direito que precisam ser enfrentadas para sua melhor inserção epistemológica, científica e prática.

\section{DADOS E A BUSCA POR ALTERNATIVAS REGULATÓRIAS}

A busca por dados precisos, confiáveis e contextualizados produzidos a partir da realidade do funcionamento dos Programas é central para o avanço da regulação da pósgraduação stricto sensu ${ }^{26}$. Ao lado da expansão e da maior profissionalização da pesquisa acadêmica na área de Direito, fator importante tanto para as mudanças positivas constatáveis como para a promoção de novas alterações destinadas a lidar com os déficits ainda existentes é o desenvolvimento de políticas educacionais voltadas a direcionar os processos de criação de novos cursos e acompanhar a qualidade da formação oferecida pelos programas e da produção intelectual dos seus docentes e discentes. Isso quer dizer que uma premissa importante deste estudo é encarar os problemas acima indicados como problemas que exigem regulação - seja ela estatal ou produto de esforços de autorregulação.

Nesse contexto, a CAPES desempenha papel central. As suas ações e diretrizes são consideradas peças importantes na dinâmica institucional de ampliação da pós-graduação stricto sensu voltada a atingir objetivos sociais importantes, como o amadurecimento da pesquisa acadêmica na área, a inserção social dos programas, a superação de assimetrias regionais, a profissionalização das atividades de pesquisa e o aumento do impacto da produção dos docentes e discentes visando, sobretudo, ao desenvolvimento nacional. Embora o termo "regulação" seja definido de diferentes maneiras ${ }^{27}$ e esteja atrelado a diferentes justificativas, passando pela tradicional visão que relaciona a sua justificação com a existência de falhas de mercado até a promoção de direitos - com destaque para direitos prestacionais, como os direitos sociais - e a solidariedade social ${ }^{28}$, não parece difícil sustentar que a CAPES se aproxima de instituições reguladoras e desempenha atividades tipicamente regulatórias. Além de traços institucionais, como a autonomia administrativa e financeira, na síntese de Nicolas Addor ${ }^{29}$, a CAPES “fiscaliza uma atividade notadamente considerada serviço público exercível pela Administração Pública e

\footnotetext{
${ }^{26}$ VERHINE, Robert E. Avaliação e regulação da educação superior: uma análise a partir dos primeiros 10 anos do SINAES. Avaliação (Campinas), Sorocaba, v. 20, n. 3, p. 603-619, nov. 2015. Disponível em: https://doi.org/10.1590/S1414-40772015000300003. Acesso em: 30 abr. 2020.

${ }^{27}$ BALDWIN, Robert; CAVE, Martin; LODGE, Martin. Understanding Regulation. Londres: Oxford University Press, 2011.

${ }^{28}$ BALDWIN, Robert; CAVE, Martin; LODGE, Martin. Understanding Regulation. Londres: Oxford University Press, 2011, p. 15 e 22.

${ }^{29}$ ADDOR, Nicolas. A regulação da pesquisa no Brasil e o modelo de avaliação Qualis Periódicos-CAPES. Dissertação (Mestrado em Direito) - Pontifícia Universidade Católica do Paraná. 2018, p.90.
} 
por particulares, que é a educação superior em nível de pós-graduação stricto sensu”. Além disso, ela "estabelece diversas políticas para fomento e fiscalização da atividade privada por meio da avaliação dos programas de pós-graduação e da concessão de bolsas e auxílios financeiros para projetos de pesquisa nas instituições de ensino superior”30.

$O$ contexto regulatório no âmbito do qual as atividades da CAPES se inserem produz um sistema normativo-institucional específico ${ }^{31}$, que busca aderência às peculiaridades da pósgraduação, abre-se à participação da sociedade, especialmente dos grupos afetados por escolhas regulatórias, e se submete a controle de organismos institucionais e sociais ${ }^{32}$. A avaliação dos Programas é uma parte importante desse sistema, mas, ainda que a legislação brasileira estabeleça uma forte relação entre avaliação e regulação no contexto da educação superior, as duas atividades não se confundem ${ }^{33}$. Nesse sentido, a busca por mecanismos restritivos ou proibitivos de comportamentos capazes de impedir o alcance de objetivos regulatórios (em uma perspectiva regulatória de "sinal vermelho") ou de meios aptos a induzir, possibilitar ou facilitar a realização desses propósitos (nas lentes de uma regulação de "sinal verde") 34 não se esgota no aperfeiçoamento constante das práticas avaliativas, ainda que elas sejam centrais.

A busca por alternativas regulatórias deve ser considerada parte importante no processo de amadurecimento da pós-graduação, o que justifica ainda mais a apresentação de informações sobre a sua realidade, na medida em que tais dados podem ser úteis tanto para a descrição apurada do seu funcionamento como para a avaliação de políticas específicas destinadas a medir se os esforços regulatórios para ampliar a profissionalização na área de Direito têm produzido a maturidade que se espera na formação e na produção científica. Esse pode ser visto como mais um argumento favorável ao desenvolvimento do tipo de análise que este trabalho propõe.

\footnotetext{
30 Ibidem.

31 HAMADA, Guilherme Henrique. O sistema regulatório de avaliação dos programas stricto sensu no Brasil. Dissertação (Mestrado em Direito) - Pontíficia Universidade Católica do Paraná. 2017, p. 86

32 MARQUES NETO, Floriano Peixoto de Azevedo. Nova regulação dos serviços públicos. Revista de Direito Administrativo, Rio de Janeiro, v. 228, p. 13-30, abr. 2002. ISSN 2238-5177. Disponível em: http://bibliotecadigital.fgv.br/ojs/index.php/rda/article/view/46521. Acesso em: 30 Abr. 2020. DOI:http://dx.doi.org/10.12660/rda.v228.2002.46521.

33 VERHINE, Robert E. Avaliação e regulação da educação superior: uma análise a partir dos primeiros 10 anos do SINAES. Avaliação (Campinas), Sorocaba, v. 20, n. 3, p. 603-619, nov. 2015. Disponível em: https://doi.org/10.1590/S1414-40772015000300003. Acesso em: 30 abr. 2020.

${ }^{34}$ BALDWIN, Robert; CAVE, Martin; LODGE, Martin. Understanding Regulation. Londres: Oxford University Press, 2011.
} 


\title{
3 EXPANSÃO E INSTITUCIONALIZAÇÃO DOS PROGRAMAS DE PÓS- GRADUAÇÃO EM DIREITO NO BRASIL
}

Toda área de conhecimento, à medida que se expande e ganha movimento próprio, carece de uma análise mais aprofundada sobre (i) os caminhos seguidos, (ii) suas principais escolas e teorias dominantes e (iii) quais metodologias são utilizadas para a construção de sua argumentação científica. A expansão dos cursos de pós-graduação em uma determinada área é fundamental para que haja uma constante renovação de quadros de pesquisa e pensamento e dê oxigenação às agendas de pesquisas que serão determinantes para definir as preocupações dentro das suas fronteiras. No gráfico 1 abaixo vê-se o movimento de expansão da pós-graduação em Direito desde o ano de 1998 até 2017. Em 20 anos, o número de PPGD quase quadruplicou, levando, em consequência, a um aumento na oferta e demanda de suas vagas. ${ }^{35}$

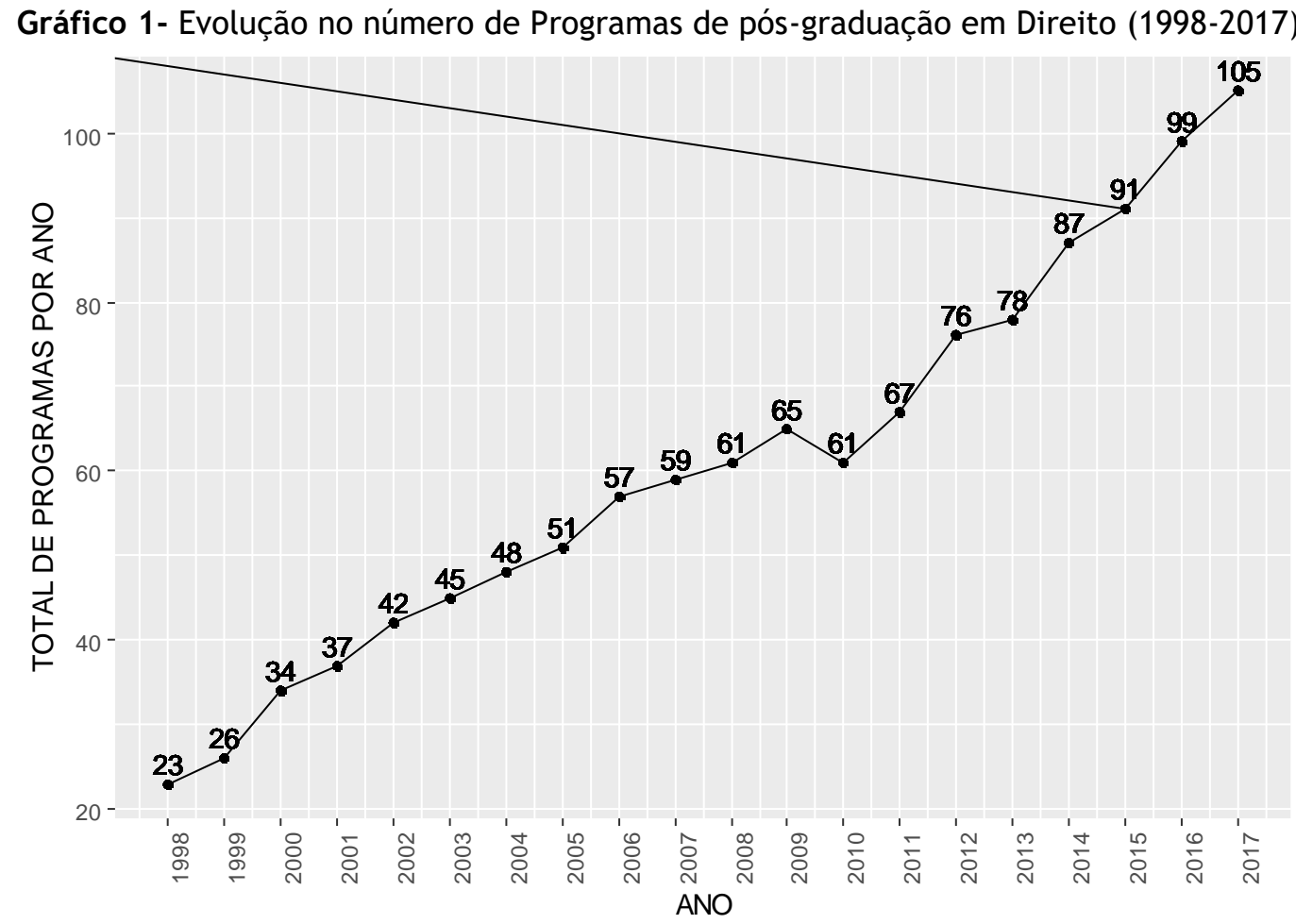

Fonte: Elaboração própria a partir dos dados do GeoCAPES.

\begin{abstract}
35 Os dados revelam a tendência já indicada por Varella em trabalho publicado em 2015. Segundo o autor, “[n]os últimos dez anos, o número total de cursos saltou de pouco mais de 20 para cerca de 80 . 0 número de Doutorados em Direito avançou de pouco mais de cinco cursos para 31". VARELLA, Marcelo. Quem influencia a pós-Graduação em Direito no Brasil? Uma análise empírica da nucleação acadêmica. Revista de Direito Brasileira, Florianópolis, v. 12, p. 112, 2015. Disponível em: https://www.indexlaw.org/index.php/rdb/article/view/2817/2669 . Acesso em: 3 dez. 2021.
\end{abstract}


Essa evolução foi crescente em todos os graus da pós-graduação, havendo inclusive a introdução de cursos de mestrado profissional a partir de 2013, o que indicou a necessidade e a possibilidade de a área criar quadros mais técnicos para determinados assuntos. Em 1998 havia 12 programas de mestrado e $11 \mathrm{com}$ mestrado e doutorado em Direito no Brasil, totalizando 23 cursos. Em 2017, esse número já chegava a 63 cursos de mestrado, 6 de mestrado profissional e 36 de mestrado e doutorado, configurando 105 cursos na área. A evolução do número de cursos por seu grau de titulação pode ser visualizada no gráfico 2 .

Gráfico 2 - Número de programas oferecidos por ano e por grau de titulação. (1998-2017)

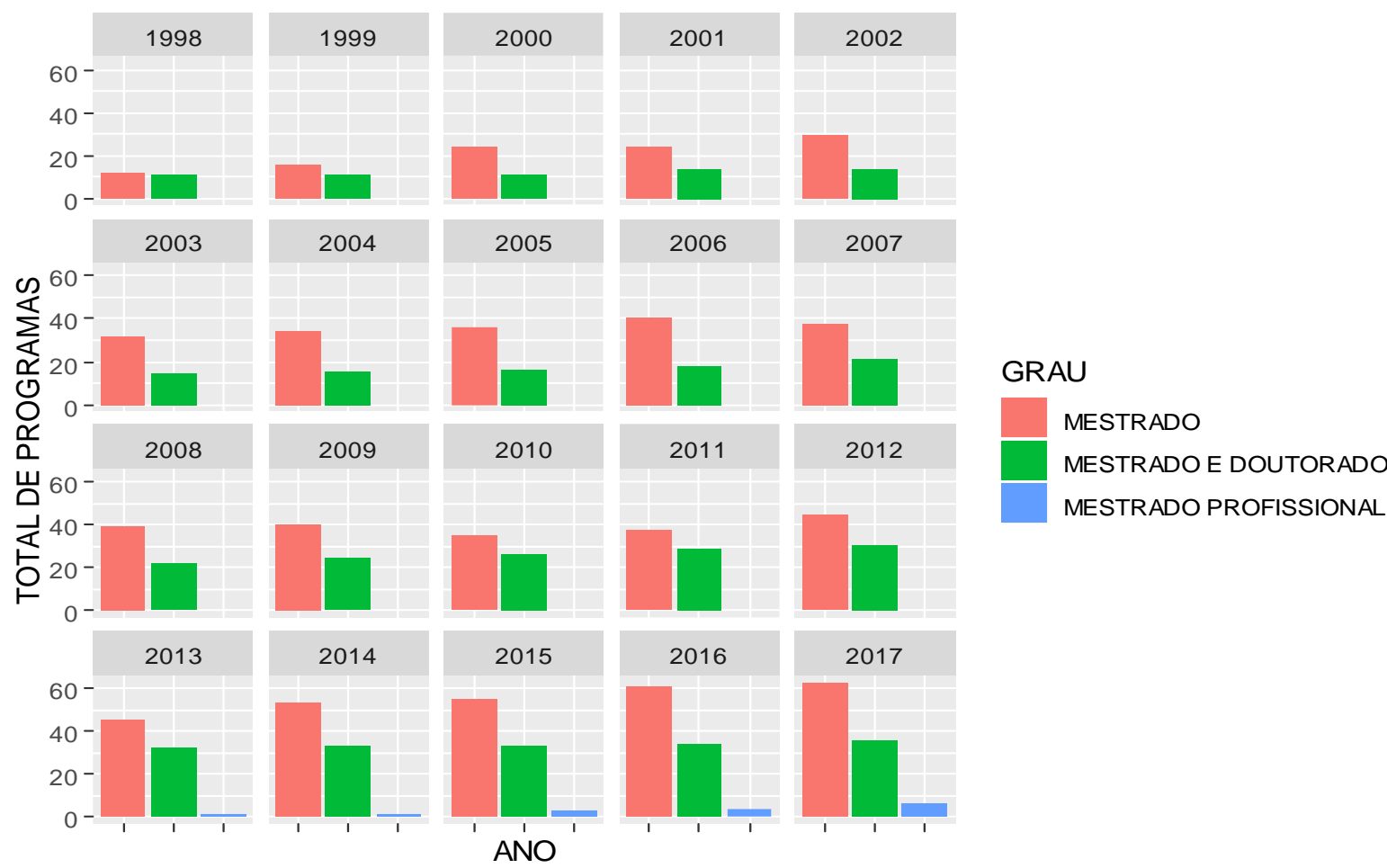

Fonte: Elaboração própria a partir dos dados do GeoCAPES.

É interessante notar que essa expansão contribuiu para que, aos poucos, surgissem programas com novos temas e fora das grandes áreas ou ramos tradicionais do Direito (ver o Anexo 1). A implementação formal da pós-graduação no país se deu em 1965 por meio do Parecer $\mathrm{n}^{\circ}$. 977 do Conselho Federal de Educação ${ }^{36}$, mas os primeiros programas de pósgraduação em Direito no Brasil foram criados na década de 1970, em pleno regime militar. Entre

36 DOTTA, Alexandre Godoy. A estrutura e o financiamento da pós-graduação no Brasil no contexto do desenvolvimento do serviço público de educação. Administrativo \& Constitucional, Belo Horizonte, v. 14, n. 56, 20 229-245, 2014. http://www.revistaaec.com/index.php/revistaaec/article/view/100 . Acesso em: 30 abr. 2020. 
eles estão: USP, em 1971; UFPE e PUC/RJ, em 1972; PUC/SP, em 1973; UFSC e UFRJ ${ }^{37}$, em 1974; UNB e UFBA, em 1975; UFC, em 1977 e UEL, UFMG e UGF ${ }^{38}$ em 1978 ${ }^{39}$. Muitos desses Programas desempenham um papel central no sistema brasileiro de pós-graduação, não só pelo conhecimento reconhecido como relevante por pesquisadores da área, mas especialmente na influência que exercem na formação do corpo docente de programas criados posteriormente ${ }^{40}$. Todos aqueles programas se organizavam em torno de áreas de pesquisa mais tradicionais e foram construídos como “mestrado em Direito" ${ }^{41}$, mantendo temáticas próximas às de atuação dos aplicadores do Direito e retratando, assim, a forte relação entre prática profissional e atividade acadêmica apontada acima. Apenas a partir da década de 1990, com a expansão dos programas, tornou-se constatável maior variação das linhas de pesquisa e áreas de concentração. A partir principalmente de 2010, as agendas de pesquisa dos programas ficam cada vez mais heterogêneas e mais abertas a abordagens interdisciplinares (Conforme Anexo 1).

São parte desta expansão mais heterogênea, apenas para citar os programas criados em 2014, por exemplo, os mestrados acadêmicos em “Direito da Regulação” na FGV Direito Rio, em "novos direitos, novos sujeitos" na UFOP em 2017 e o mestrado profissional em "Direito Tributário Internacional e Desenvolvimento" no IBDT/SP, também em 2017. Esses são alguns poucos exemplos que revelam como houve uma expansão nos temas discutidos pelos PPGD, fato que contribuiu para a ampliação das pesquisas no Direito. Essa expansão na agenda de estudos foi possível graças ao aumento da oferta de cursos, mas poderia também ser explicada em função da demanda discente em busca de conhecimentos especializados, que passou a encontrar programas com áreas de concentração e linhas de pesquisa mais próximas dos seus interesses acadêmicos.

37 O Programa de Ciências jurídicas da UFRJ criado em 1974 encontra-se desativado, mas a plataforma Sucupira não informa a data de desativação deste programa.

${ }^{38}$ A Universidade Gama Filho deu início a seu mestrado em Direito em 1978 e ao seu Doutorado em 1991, ambos tendo sido desativados em 2014.

${ }^{39}$ Os dados sobre o ano de início dos programas foram retirados do site da CAPES e podem ser consultados nas bases de dados dos autores. Analisamos os programas em funcionamento/desativados e consultamos seu ano de início/fim. Para consultar programas em funcionamento, em projeto e desativados ver : PLATAFORMA SUCUPIRA. CAPES. Disponível https://sucupira.capes.gov.br/sucupira/public/consultas/coleta/programa/listaPrograma.jsf?acao=pesqui sarAreaftcodigoGrandeArea $=60000007 \&$ descricaoGrandeArea $=$ CI\%25CANCIAS+SOCIAIS+APLICADAS+ . Acesso em: 29 abr. 2021.

40 V. VARELLA, op. cit e GAMEIRO, lan Pimentel; GUIMARÃES FILHO, Gilberto. O mapa da pós-graduação em Direito no Brasil: uma análise a partir do método da Social Network Analysis. Revista Direito GV, [s.l.], v. 13, n. 3, p. 891-920, jan. 2018. ISSN 2317-6172. Disponível em: http://bibliotecadigital.fgv.br/ojs/index.php/revdireitogv/article/view/73332. Acesso em: 30 Abr. 2020. ${ }^{41}$ Informações retiradas do site da CAPES que também fazem parte da base de dados dos autores. 
ISSN 1981-3694

(DOI): $10.5902 / 1981369447110$

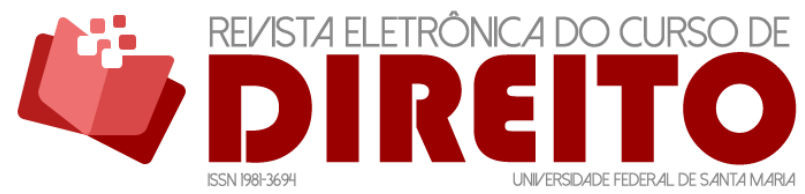

A EXPANSÃO DA PÓS-GRADUAÇÃO EM DIREITO NO BRASIL (19982017): AVANÇO OUANTITATIVO E PERSISTÊNCIAS METODOLÓGICAS

DÉCIO VIEIRA DA ROCHA FERNANDO LEAL

A expansão dos programas de mestrado e doutorado em Direito pode ser visualizada, também, no aumento dos discentes (gráficos 3 e 4 abaixo). 0 número de matrículas nesses programas mais que duplicou nesses 20 anos. No caso dos mestrados profissionais, autorizados mais recentemente, nota-se um rápido crescimento, que, se mantido em ritmo semelhante, poderá torná-los cada vez mais relevantes no sistema de pós-graduação stricto sensu no país.

Gráfico 3 - Evolução de matrículas discentes nos programas de ME, DO e MP42 (1998-2017).

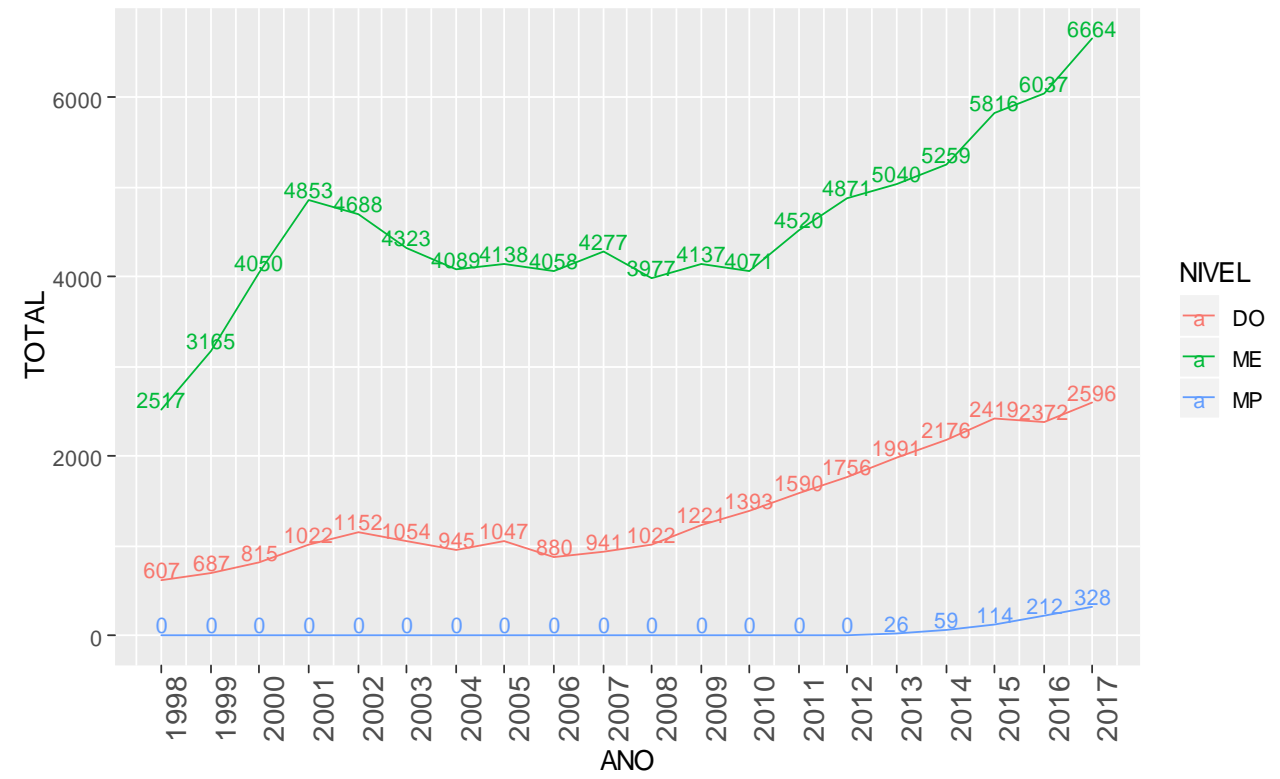

Fonte: Elaboração própria a partir dos dados do GeoCAPES.

Gráfico 4 - Evolução de titulações discentes nos programas de ME, DO e MP (1998-2017).

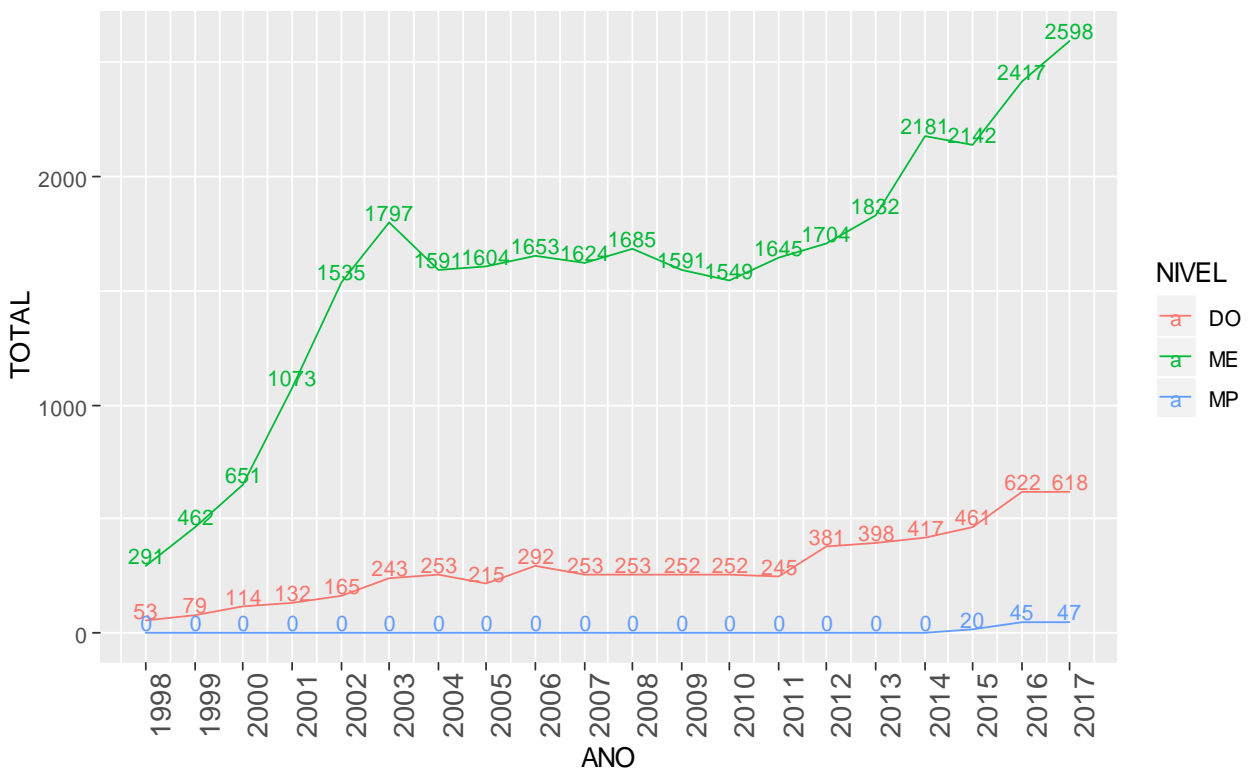

Fonte: Elaboração própria a partir dos dados do GeoCAPES.

${ }^{42} \mathrm{ME}=$ Mestrado acadêmico. $\mathrm{DO}=$ Doutorado acadêmico. $\mathrm{MP}=$ Mestrado Profissional. 
Com o foco apenas no sistema de pós-graduação, quatro fatores mostram-se relevantes para explicar a rápida e significativa expansão identificada. Em primeiro lugar, o rápido crescimento do número de faculdades de Direito no país produziu mais instituições interessadas em ingressar no sistema. Em segundo lugar, o excesso de programas com áreas de concentração muito próximas, às vezes na mesma cidade ou região, pode ter produzido certa saturação na formação de mestres e doutores. Além disso, a existência de programas consolidados em determinados temas aumentava os custos dos novos entrantes, que precisavam competir com cursos mais tradicionais. Em terceiro lugar, é possível que houvesse demanda reprimida da parte de pesquisadores e operadores do direito por cursos com temáticas que evidenciassem maior especificidade, atualidade e multidisciplinaridade. Em quarto lugar, finalmente, a área de Direito passou a adotar, na década passada, diretrizes regulatórias que incentivavam a apresentação de propostas de cursos novos em áreas menos tradicionais, especialmente buscando a diferenciação dos programas e evitar sobreposições temáticas em excesso, sobretudo na mesma região de ingresso do novo PPGD ${ }^{43}$.

Como consequência de aspectos mercadológicos e regulatórios, temas como políticas ambientais, acesso à justiça, judicialização dos processos sociais e políticos, políticas de drogas e encarceramento, efeitos de regras eleitorais no sistema político e combate à pobreza, entre tantos outros que estavam mais ligados à Sociologia, Economia, Serviço Social, Ciência Política e áreas próximas ao Direito, começaram a ser introduzidos como linhas de pesquisa nos novos programas, ampliando as novas agendas de pesquisa possíveis dentro da pós-graduação stricto sensu em Direito ${ }^{44}$.

Outro fator explicativo para o aumento das matrículas e titulações discentes pode estar relacionado ao fato de que, com a expansão da pós-graduação, conquistar um título mais alto se tornou cada vez mais necessário e parte de uma disputa pelos espaços docentes que se tornaram cada vez mais concorridos. Se houve, por um lado, um aumento de cursos de Direito e instituições postulantes ao ingresso no sistema de pós-graduação stricto sensu, houve, como

\footnotetext{
${ }^{43}$ Diretrizes nesse sentido podem ser observadas, por exemplo, no Documento Orientador de APCN para a área do Direito de 2019. Especificamente a seção que trata da proposta do curso indica a necessidade de a proposta considerar, entre outros fatores, a demanda regional por formação na área e a "a diferenciação da proposta em relação aos programas já inseridos no sistema da pós-graduação, tomando-se como critério primário a região (metropolitana ou microrregião) e, como critério secundário, a unidade da federação, onde o curso pretenderá funcionar." BRASIL. CAPES. Documento orientador de APCN: Área 26: Direito. [s.l], 2019, p. 5. Disponível em: https://www.gov.br/capes/pt-br/centrais-deconteudo/documentos/avaliacao/APCN_DIREITO.pdf . Acesso em: 3 dez. 2021.

${ }^{44}$ Essas agendas de pesquisa serão vistas mais à frente quando avaliarmos os periódicos nacionais e internacionais centrais na área e suas principais linhas de editoração.
} 
reflexo, o aumento da demanda por docentes qualificados. Com isso, passam a surgir docentes que vivem exclusivamente da docência, como evidencia o estudo de Maria Glória Bonelli ${ }^{45}$, o que modificou, mesmo que em nível ainda baixo, a antiga lógica de operadores do direito que transitam entre a vida acadêmica e a vida profissional na área ${ }^{46}$.

O número de docentes que tendem cada vez mais a ter a vida acadêmica como atividade central também pode ser visualizado no gráfico 5 abaixo, que mostra como o número de docentes permanentes cresceu a partir de 2003 e se tornou majoritário nos programas de pósgraduação em Direito. Pelas diretrizes da CAPES, programas de mestrado e de doutorado devem contar com ao menos 10 docentes atuando em tempo integral e de forma exclusiva ${ }^{47}$. Essa medida regulatória afeta diretamente a composição do quadro docente.

Gráfico 5 - Evolução do número de docentes nos PPGD por vínculo (1998-2017).

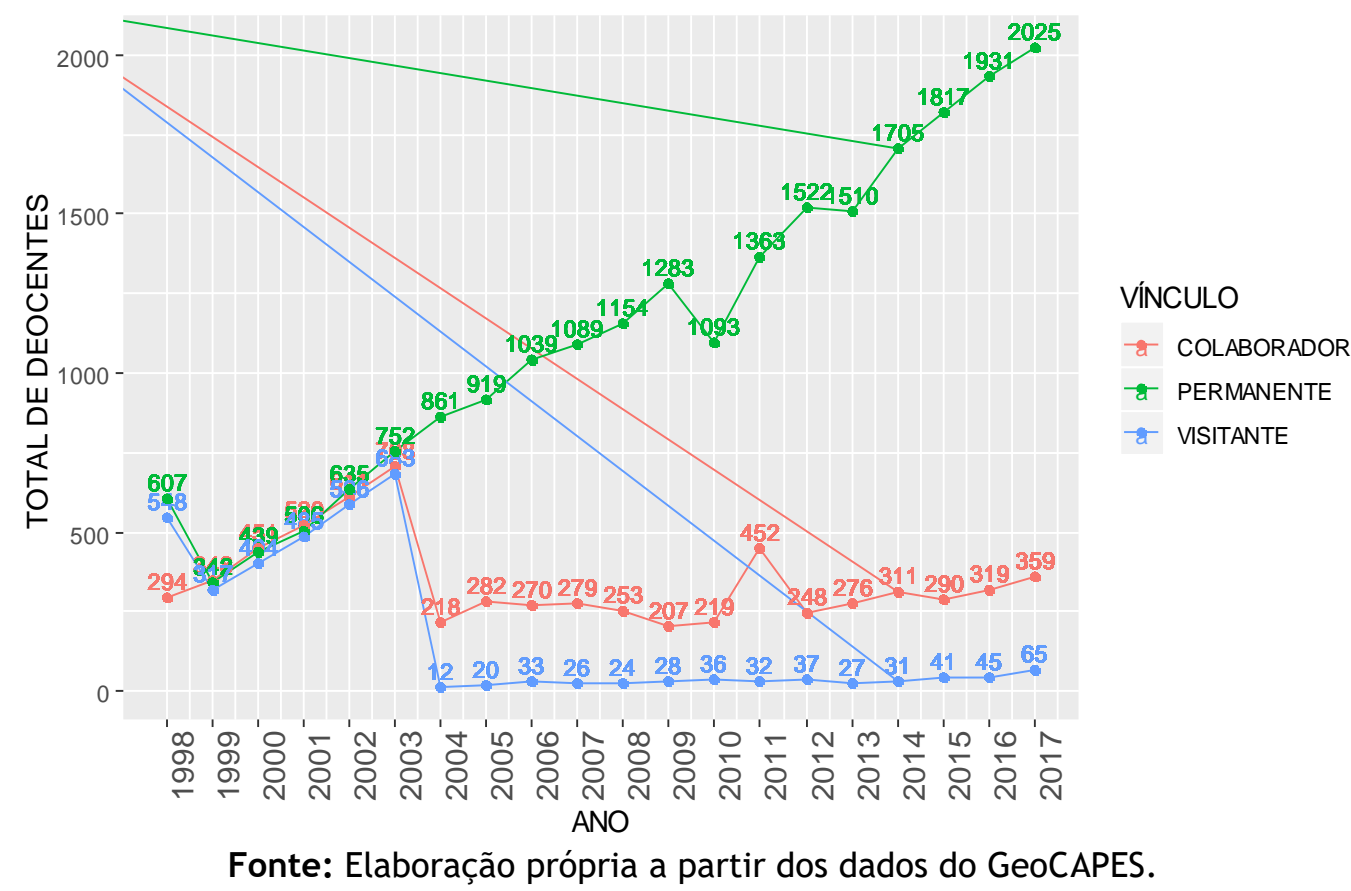

45 BONELLI, Maria da Gloria. Os sentidos da docência do Direito: discursos, identidades e diferenças. In. Associação Brasileira de Pesquisa em Ciências Sociais. ANPOCS. 2018. Caxambu, MG. Anais... (on-line). Disponível em: https://www.anpocs.com/index.php/papers-40-encontro-3/gt-31/gt21-25/11295-ossentidos-da-docencia-do-direito-discursos-identidades-e-diferencas/file

${ }^{46}$ ALMEIDA, Elizangela Santos de Almeida. A Formação Stricto Sensu dos Professores dos Cursos de Direito e seus Reflexos no Ensino Jurídico. Dissertação (Mestrado em Educação) - Universidade de Uberaba - UNIUBE, Uberaba, MG, 2014, p. 42-45. Disponível em:

https://www.uniube.br/propepe/ppg/educacao/arquivos/2014/listaDissertacoes/Dissertacao-

Elizangela.pdf. Acesso em: 29 abr. 2020.

47 O APCN para a área do Direito lista uma série de exigências relacionadas ao regime de dedicação e qualificação mínima dos docentes permanentes. Ver MEC/CAPES/DAV. Documento Orientador de APCN para área do Direito, 2016 e 2019. Para uma visão mais abrangente dos documentos ver; https://www.gov.br/capes/pt-br/centrais-de-conteudo/Criterios_APCN_Direito.pdf https://www.gov.br/capes/pt-br/centrais-de-conteudo/documentos/avaliacao/APCN_DIREITO.pdf. 
Chama a atenção no gráfico acima o alto número de docentes colaboradores e visitantes nos programas. Essas duas categorias ficavam quase próximas ao número de docentes permanentes até 2003, quando começam a desempenhar um papel menor relativamente ao número destes últimos. A partir de 2004, como se nota, as duas categorias (colaboradores e visitantes) se estabilizam, enquanto o número de docentes permanentes segue em crescimento, o que parece expressar uma preferência dos programas por docentes que se dedicam mais diretamente às atividades de ensino e pesquisa. Um outro indicador importante desse aprimoramento de docentes e de pesquisadores pode ser visualizado no gráfico 6 , abaixo.

Gráfico 6 - Evolução do número de docentes por titulação de doutores e não-doutores (1998-2017)

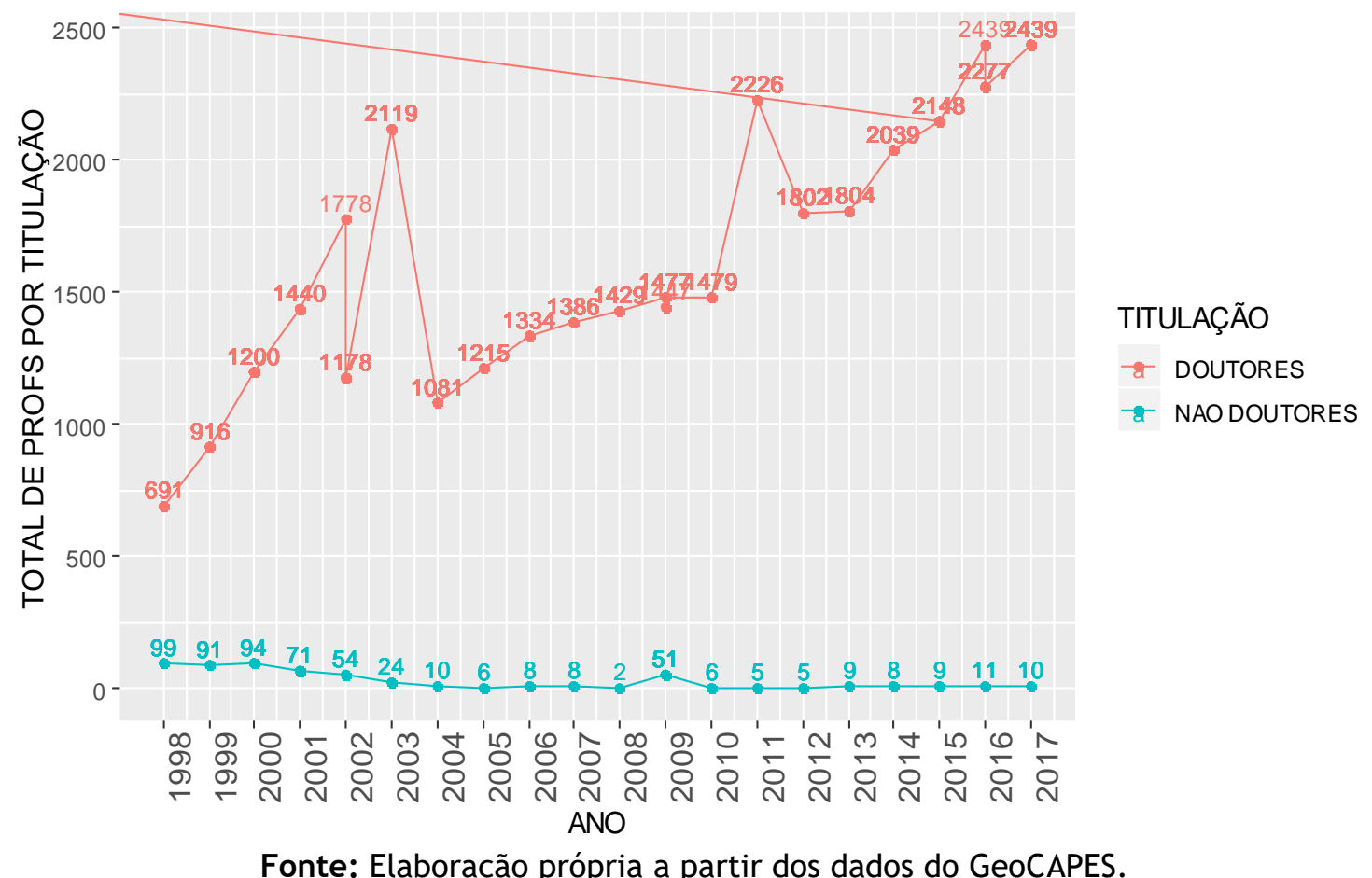

Embora o número de não doutores no corpo docente dos programas de pós-graduação tenha sido baixo desde o início da série histórica analisada, enquanto em 1998 o somatório de professores não doutores chegava a quase 100, distribuídos em poucos programas, em 2017 havia apenas 10 docentes nessa categoria ${ }^{48}$. Esses dados mostram como as diretrizes da CAPES têm contribuído para o alcance de objetivos regulatórios na área de direito, como a aumento de

\footnotetext{
48 Desses, não havia mais de um professor não Doutor por programa. Como não temos informações dos nomes dos professores não podemos dizer com certeza o papel deles nestes programas, mas por intuição acredita-se que são nomes importantes na estrutura judiciária (magistrados, promotores, etc.) que são convidados a participar do corpo docente de programas, sobretudo profissionais.
} 
docentes doutores nos quadros dos PPGD e vocacionados à dedicação exclusiva a atividades acadêmicas. Essa é uma evidência clara de como políticas institucionais que induzem todos os programas a seguirem diretrizes universalmente orientadas garantem redução de esforços e de problemas de ação coletiva, produzindo melhorias em todas as áreas do conhecimento e, principalmente, no Direito, que tradicionalmente sobrepõe qualidade acadêmica com sucesso profissional em carreiras relacionadas à operação prática do direito, como a advocacia e a magistratura.

A expansão nos investimentos e a criação de diretrizes para incentivar maior independência e profissionalização de posições acadêmicas na área de Direito contribuíram também para a expansão de associações de ensino e pesquisa, como a ABEDI (Associação Brasileira de Ensino do Direito) e, especialmente, o CONPEDI (Conselho Nacional de Pesquisa e Pós-Graduação em Direito). O CONPEDI, como associação, realiza encontros anuais desde 1992, contribuindo para a circulação do conhecimento e do resultado de projetos de pesquisas em Direito ${ }^{49}$.

A expansão em todos esses níveis de ensino e pesquisa veio também acompanhada de uma mudança bastante significativa: o aumento da oferta de cursos de pós-graduação em Direito em instituições de ensino privadas. Até o fim da década de 1980, grande parte dos cursos de pós-graduação em Direito estavam vinculados a Universidades Federais. Poucos eram os Programas presentes em universidades estaduais (apenas a USP) e privadas (casos, por exemplo, das PUC de SP, RJ, RS e da Universidade Gama Filho). O sistema de programas pós-graduação em Direito manteve-se centrado nos primeiros cursos criados na década de 1970 já citados anteriormente, tendo na década de 1980 incorporado apenas 5 novos programas (UFPR, UFRGS, UFPA, UFG ${ }^{50}$ e PUC/RS ${ }^{51}$ ). É na década de 1990, contudo, que se constata relevante alteração do quadro, com o estabelecimento de novos Programas em universidades estaduais (UNESP/Franca, UERJ) e universidades privadas mais tradicionais (UNESA, UCAM, UNIVALI, UNISINOS, UNIMEP, FDMC, PUC/MG e PUC/RS ${ }^{52}$ ), tendo apenas uma universidade federal (UFPB) ingressado no

\footnotetext{
49 Os anais dos eventos podem ser encontrados em: https://www.conpedi.org.br/quemsomos/eventos/ , acessado em 06-05-2020.

50 O PPG em Direito da UFG iniciado em 1985 foi desativado em 2005.

51 Mais uma vez, é importante salientar, o ano de início dos programas foi retirado do site da CAPES. Para consultar programas em funcionamento, em projeto e desativados ver : https://sucupira.capes.gov.br/sucupira/public/consultas/coleta/programa/listaPrograma.jsf?acao=pesqui sarArea\&codigoGrandeArea=60000007\&descricaoGrandeArea=CI\%25CANCIAS+SOCIAIS+APLICADAS + / , acessado em 29-04-2020.

52 A PUC/RS aparece duas vezes (década de 80 e 90) porque em 1988 iniciou um mestrado em Direito e em 1997 abriu um novo curso de Ciências Criminais.
} 
sistema no período. Mas, o mais interessante é que essa tendência de surgimento de programas de pós-graduação stricto sensu em instituições privadas, que ganha corpo nos anos 1990, ganhou ainda mais força ao longo do tempo, fazendo com que a oferta de vagas em suas fronteiras ultrapassasse a oferta em instituições públicas de ensino ${ }^{53}$. No gráfico 7 , visualiza-se claramente a dominância de instituições privadas após os anos 2000. Em 2017, o aumento no número de cursos oferecidos por IES privadas é seis vezes maior do que o existente em 1998. Esse ritmo de crescimento não se constata em instituições federais de ensino, ainda que os PPGD ofertados por elas tenham dobrado entre 1998 e 2017. No universo específico das universidades estaduais, o ritmo de crescimento é muito baixo, chegando a haver decréscimo no número de programas em 2007.

Gráfico 7 - Evolução dos programas de Direito por seu status jurídico (1998-2017).

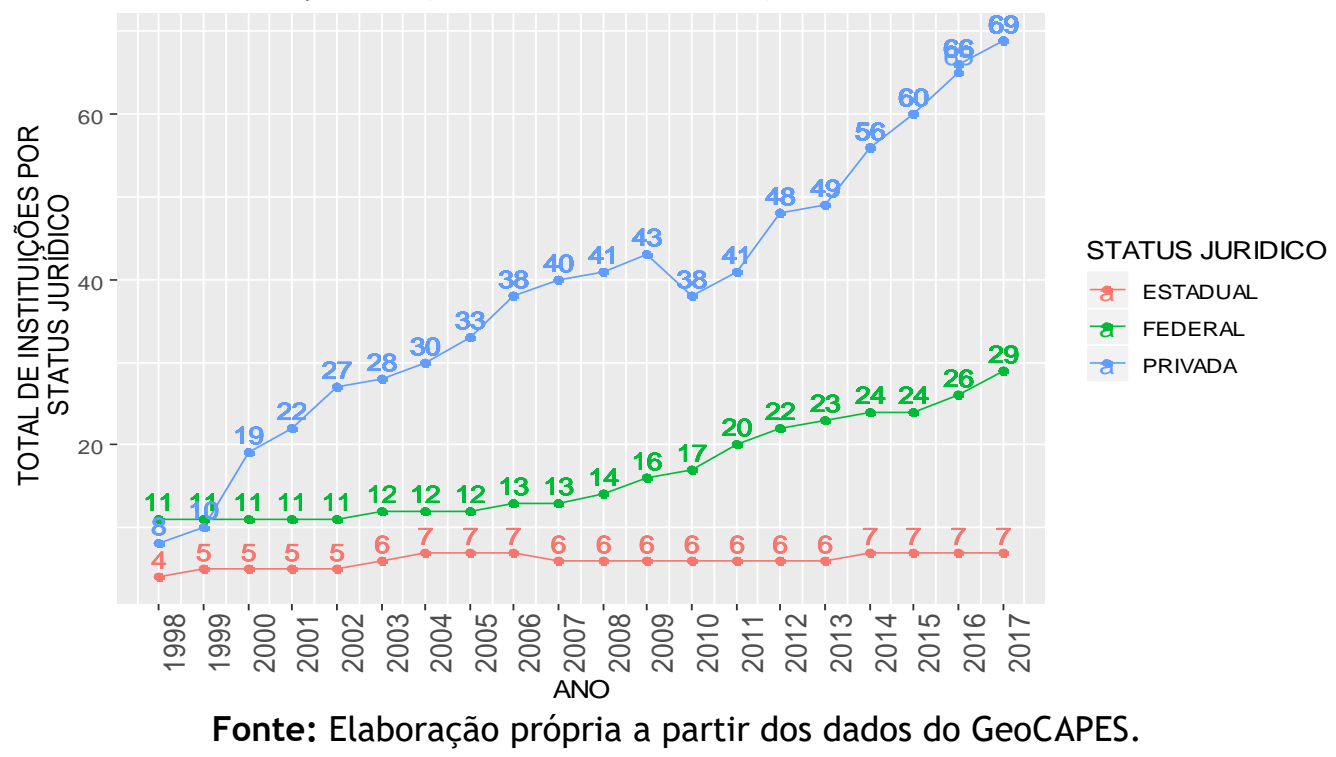

A constatação de aumento significativo no número de programas, docentes e discentes exigiu também uma ampliação na própria estrutura acadêmica da área, que passou a demandar mais periódicos especializados e eventos científicos capazes de garantir a circulação de ideias, o

\footnotetext{
${ }^{53} \mathrm{O}$ aumento da participação de instituições privadas na pós-graduação também é perceptível em outras áreas. Segundo Alexandre Dotta, "é possível perceber crescimento da participação do setor privado: em 2004 detinha 14\% dos cursos de pós-graduação; essa taxa aumentou em 2009 para 17\%. Todavia não se pode deixar de destacar que o setor privado foi o que mais cresceu: teve $61 \%$ de aumento frente a $34 \%$ do setor público. 0 crescimento está localizado principalmente nos cursos de mestrado e de doutorado, pois no mestrado profissional a proporção se manteve igual durante o período analisado". DOTTA, Alexandre Godoy. A estrutura e o financiamento da pós-graduação no Brasil no contexto do desenvolvimento do serviço público de educação. Administrativo \& Constitucional, Belo Horizonte, v. 14, n. 56, p. 231, 2014. Disponível em: http://www.revistaaec.com/index.php/revistaaec/article/view/100 . Acesso em: $30 \mathrm{abr}$. 2020.
} 
aprimoramento e a expansão dos temas estudados. Esse robustecimento paulatino do sistema se revela importante, na medida em que possibilita maior heterogeneidade de metodologias, sobretudo pelo avanço da pesquisa empírica no Direito, a consolidação de novas linhas de pesquisa e maiores níveis de autonomização da disciplina como uma área de produção de conhecimento científico. Ou seja, a própria expansão dos PPGD pode levar a médio e longo prazo a área em análise a operar em uma dinâmica acadêmica menos ligada à lógica profissionalizante que originalmente caracterizou a oferta de cursos de Direito e mais relacionada às atividades de ensino e pesquisa produzidas nas demais ciências sociais e humanas.

\section{PRODUÇÃO E IMPACTO}

Importante elemento para a autonomização mencionada no parágrafo anterior é a ampliação dos periódicos especializados da área do Direito, capazes de garantir a circulação, a divulgação, a acessibilidade e a troca entre pesquisadores dos “produtos” (artigos, pareceres, notas técnicas, resenhas, agendas de pesquisa) construídos nos PPGD. Tal expansão, acompanhada de diretrizes regulatórias voltadas a induzir constantemente o aumento da qualidade e do impacto das produções, como as que inspiram o sistema Qualis ${ }^{54}$, revela-se, ainda, central, na medida em que a produção intelectual desempenha tradicionalmente papel fundamental para a avaliação dos programas, especialmente a partir de 1998, quando o sistema atual por notação é estabelecido e o Qualis Periódicos é criado ${ }^{55}$. Por esse motivo, cotejar a

\footnotetext{
${ }^{54}$ ADDOR, Nicolas. A regulação da pesquisa no Brasil e o modelo de avaliação Qualis Periódicos-CAPES. Dissertação (Mestrado em Direito) - Pontifícia Universidade Católica do Paraná. 2018.

55 "O sistema de avaliação dos programas de pós-graduação no país foi instituído pela Coordenação de Aperfeiçoamento de Pessoal do Ensino Superior (Capes) em 1977". BARRADAS BARATA, R. DE C. Dez coisas que você deveria saber sobre o Qualis. Revista Brasileira de Pós-Graduação, v. 13, n. 30, 22 dez. 2016, p.14. Em um primeiro momento, como indica Alexandre Dotta, a CAPES "estabeleceu critérios e parâmetros que classificavam os cursos e programas com conceitos de A (melhor) até E (pior). Algumas modificações que ocorreram gradativamente na metodologia de avaliação da CAPES ao longo do tempo foram as seguintes: em 1980 iniciou o procedimento de visitas de pares aos cursos; em 1982 foi iniciada a divulgação dos resultados individuais para a IES; em 1984 foi autorizada a solicitação de reconsideração da avaliação; em 1985 iniciou-se a divulgação dos conceitos da avaliação para todos os cursos; em 1988 estreou a utilização da informática no processo; e, em 1992 foram incluídos indicadores qualitativos e quantitativos nas avaliações, além de ter sido separado o procedimento em duas etapas". DOTTA, Alexandre Godoy. A estrutura e o financiamento da pós-graduação no Brasil no contexto do desenvolvimento do serviço público de educação. Administrativo \& Constitucional, Belo Horizonte, v. 14, n. 56, p. 233, 2014. Disponível em: http://www.revistaaec.com/index.php/revistaaec/article/view/100 . Acesso em: 30 abr. 2020. O modelo atual foi implementado em 1998. Nele, como sintetiza Dotta, "os programas são classificados por notação, que pode chegar até sete para os que possuem os dois níveis (mestrado e doutorado), e no máximo nota cinco para os que ofertam somente o primeiro nível. A avaliação é obrigatória e subsidia a alocação de verbas, bolsas e financiamento de projetos. A política e estratégias para a regulação determinadas pela CAPES para a pós-graduação produzem efeitos
} 
ISSN 1981-3694

(DOI): $10.5902 / 1981369447110$

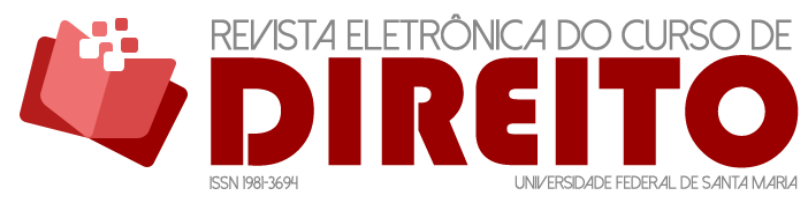

A EXPANSÃO DA PÓS-GRADUAÇÃO EM DIREITO NO BRASIL (19982017): AVANÇO QUANTITATIVO E PERSISTÊNCIAS METODOLÓGICAS

DÉCIO VIEIRA DA ROCHA FERNANDO LEAL LEANDRO MOLHANO RIBEIRO

expansão dos PPGD com dados sobre a sua produção se revela peça central, ainda que não exclusiva, para a avaliação da efetividade das políticas regulatórias voltadas à promoção da qualidade do sistema como um todo.

Com esse objetivo em mente, para a obtenção de um retrato de como está disposta a produção de conhecimento na área de Direito, analisou-se as duas últimas avaliações do Qualis Periódicos $^{56}$ (2010-2012 e 2013-2016), visando a entender como se dá a distribuição dos principais periódicos nos estratos superiores do sistema (A1 e A2). Nos gráficos 8 e 9 observa-se a evolução dos periódicos nas duas últimas avaliações.

Gráfico 8 - Quantitativo de periódicos A1 e A2 na área de avaliação de Direito no triênio 2010-2012.

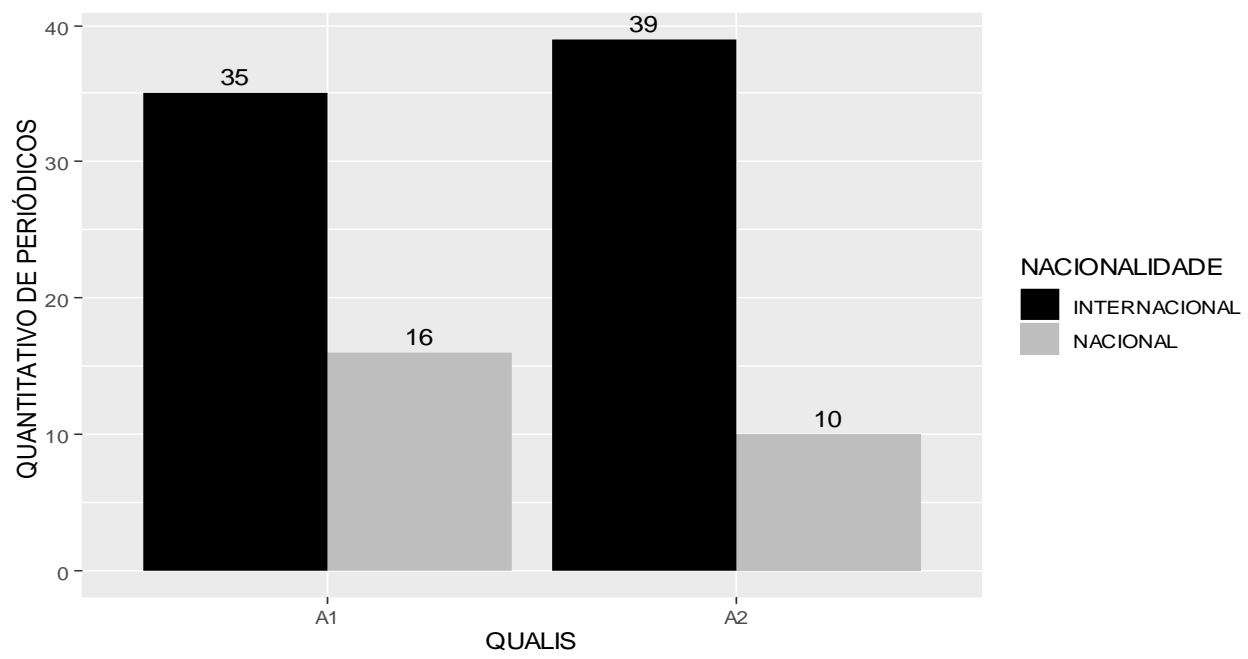

Fonte: Elaboração própria a partir do Qualis Capes da plataforma Sucupira.

pedagógicos, políticos e econômicos. Ademais, é alimentado "o espírito de competitividade e de concorrência individual ou interinstitucional", para tanto utilizando as políticas de financiamento não só como investimento individual, mas também como fomento geral ao sistema" DOTTA, Alexandre Godoy. A estrutura e o financiamento da pós-graduação no Brasil no contexto do desenvolvimento do serviço público de educação. Administrativo \& Constitucional, Belo Horizonte, v. 14, n. 56, p. 233, 2014. Disponível em: http://www.revistaaec.com/index.php/revistaaec/article/view/100 . Acesso em: 30 abr. 2020.

56 A CAPES mudou o tempo de avaliação no período, passando de avaliações trienais até 2012 para avaliações quadrienais a partir de 2013. 
Gráfico 9 - Quantitativo de periódicos A1 e A2 na área de avaliação de Direito no quadriênio 2013-2016.
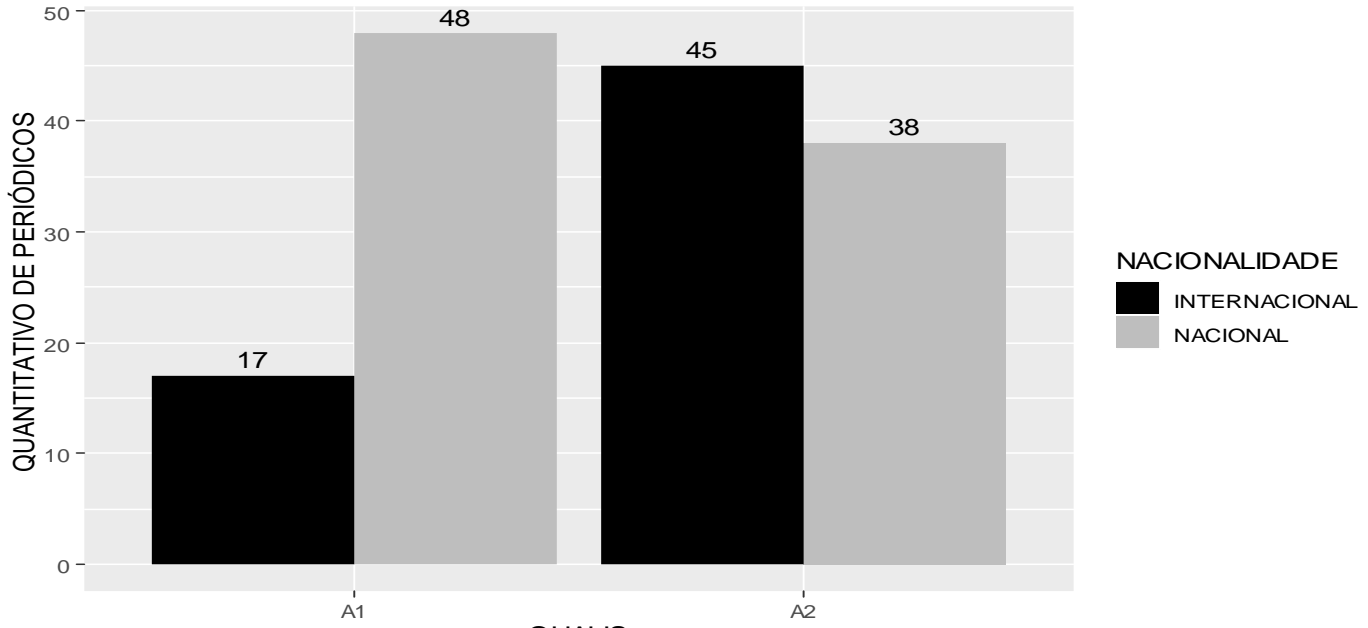

Fonte: Elaboração própria a partir do Qualis Capes da plataforma Sucupira.

Já na avaliação trienal de 2010-2012, dois anos, portanto, da implementação do sistema de avaliação de periódicos, havia um número expressivo de periódicos na área de Direito avaliados nos estratos superiores do Qualis. Entre os periódicos internacionais, 35 estavam no estrato $\mathrm{A} 1$ e, entre os nacionais, 16 periódicos se localizavam no mesmo nível. Para o estrato A2, os números eram 39 e 10 entre periódicos internacionais e nacionais, respectivamente. 0 quadro se modifica bastante na avaliação 2013-2016, com o número de periódicos internacionais caindo para apenas 17 no estrato $A 1$, enquanto nos periódicos nacionais constata-se um aumento para 48 periódicos avaliados no estrato superior, três vezes maior que o número de periódicos da avaliação anterior. Neste aspecto, parece ter havido melhorias no sistema, uma vez que revistas que não eram necessariamente do Direito saíram do estrato superior nessa avaliação, dando espaço a revistas mais diretamente ligadas à área ${ }^{57}$. No estrato A2, havia, no mesmo período, 45 periódicos internacionais, o que exprime leve aumento nesse segmento, e 38 periódicos nacionais, número quase quatro vezes maior do que o da avaliação anterior. Com essas alterações, houve um aumento significativo no número de canais de excelência para a publicação das pesquisas de docentes e discentes.

\footnotetext{
${ }^{57}$ Ao mesmo tempo, não se deve negligenciar que "o Qualis só existe como ferramenta para a avaliação de programas. Estar ou não na lista do Qualis significa tão somente que algum dos alunos ou professores dos programas credenciados publicaram artigos naqueles periódicos". BARRADAS BARATA, R. DE C. Dez coisas que você deveria saber sobre o Qualis. Revista Brasileira de Pós-Graduação, v. 13, n. 30, 22 dez. 2016, p.17. Assim, a queda de periódicos internacionais qualificados como A1 pode sugerir - ainda que essa não seja a única explicação possível - uma redução dos níveis de internacionalização - e talvez também do impacto - da produção dos Programas.
} 
Em paralelo a esses processos de ampliação de periódicos bem ranqueados, contata-se também aumento no número de documentos publicados a partir de 1998, com ampliação significativa entre 2012 e 2013 e a partir de 2015, momentos que marcam a estabilização do que se costuma designar, com juízo de valor negativo, por "produtivismo acadêmico" - "entendido como a obrigação de publicar em periódicos, como indicador praticamente exclusivo para a avaliação da produção científica e da qualidade do pesquisador" 58 . 0 gráfico 10 abaixo expressa a evolução do número de documentos publicados pelo período analisado.

Gráfico 10 - Número de documentos indexados na base Scopus por ano em periódicos da área de Direito $(1998-2017)$

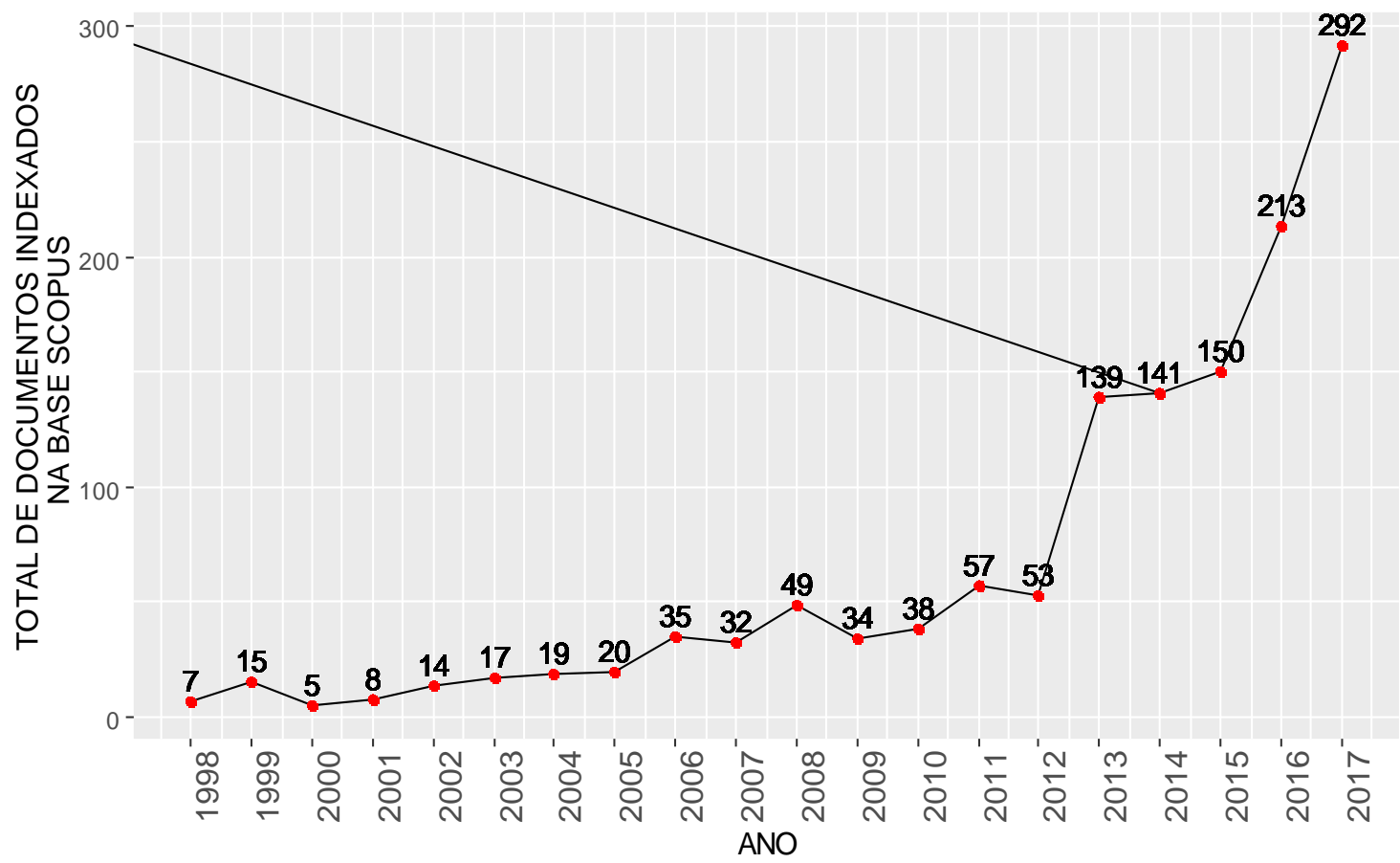

Fonte: Elaboração própria a partir dos dados Scientific Journal Rankings (SJR).

O número de documentos indexados, como se nota, deu um salto substantivo, principalmente no ano de 2013 (ano de início da coleta de dados para avaliação quadrienal 20132016). Esse aumento no número de publicações contribuiu para que a área de Direito no Brasil saltasse da posição $35^{\circ}$ em 1998 para a posição $14^{\circ}$ em 2017 no ranking de países da Scimago ${ }^{59}$. Nada obstante, um dos problemas desse ranking é que ele numera os países levando em conta

${ }^{58}$ REGO, Teresa Cristina. Produtivismo, pesquisa e comunicação científica: entre o veneno e o remédio. Educ. Pesqui., São Paulo, v. 40, n. 2, p. 325-346, jun. 2014. Disponível em: http: / / www.scielo.br/scielo.php?script=sci_arttext\&pid=S1517-97022014000200003\&lng=pt\&nrm=iso . Acesso em: 30 abr. 2020.

590 ranking de publicação dos países pode ser visto em https://www.scimagojr.com/countryrank.php?category=3308. 
apenas o número de documentos publicados que estão indexados na base Scopus ${ }^{60}$. Esse, sem dúvida, é um indicador importante, até porque, para um periódico entrar nos estratos A1 e A2 da CAPES, é obrigatório que ele esteja indexado no Scopus. Essa é uma diretriz regulatória que condiciona os periódicos do Direito a métricas de qualidade internacional. Porém, esse indicador dá uma dimensão apenas quantitativa dos produtos publicados, não revelando o impacto que essas publicações possuem dentro da área.

Para analisar o impacto, um bom critério é o índice " $h$ ", já usado em diversas áreas ${ }^{61}$, que mede o número de publicações em relação ao número de citações recebidas. Dessa forma, um índice $\mathrm{h}=3$ indica que um determinado pesquisador publicou 3 artigos com citação igual ou superior a $3^{62}$. Uma das vantagens do uso desse fator de impacto é a possibilidade de criar medidas de ranqueamento de instituições de ensino ou programas que unem produtividade (número de publicações) com impacto (número de citações).

0 índice " $h$ " para a área de Direito por todo o período analisado foi de $35^{63}$. Assim, analisando novamente o ranking de países, o índice $\mathrm{h}$ de direito do Brasil está aquém de países com menos documentos publicados como Suiça $(h=63)$, África do Sul $(h=51)$, Suécia $(h=70)$, Coréia do Sul $(h=57)$, México $(h=39)$, entre outros ${ }^{64}$. Isso revela mais reciprocidade entre produção e impacto nesses países. Esse número ainda baixo para o Brasil, evidencia que o aumento no número de documentos publicados não veio seguido de um forte impacto na área. Durante quase todo o período analisado a produção se manteve estável e o índice " $\mathrm{h}$ " também ${ }^{65}$. Ou seja, o aumento no número de documentos publicados que deveria trazer um maior impacto no número de citações de artigos importantes da área não ocorreu.

Um rápido olhar pelas revistas com maior impacto no Scielo indica que, como as áreas mais tradicionais do Direito - vinculadas aos "ramos" que definem as principais áreas de

${ }^{60}$ Scopus é uma base de dados de referências e de citações de artigos de periódicos científicos revisados por pares da comunidade.

61 BARRADAS BARATA, R. DE C. Dez coisas que você deveria saber sobre o Qualis. Revista Brasileira de Pós-Graduação, v. 13, n. 30, 22 dez. 2016.

$62 \mathrm{O}$ índice gera alguns problemas que impedem comparações entre pesquisadores pelo fato que alguns pesquisadores podem optar por publicar menos garantindo mais qualidade e consequentemente mais citações gerando o mesmo $\mathrm{H}$ que pesquisadores que são menos citados mas tem uma produção maior. Para ver melhor a este respeito, ver (Lopes. et al, 2012).

${ }^{63}$ Ver no ranking da Scimago: https: / / www.scimagojr.com/countryrank.php?category=3308.

${ }^{64}$ Para uma comparação rápida, em 2017 o Brasil publicou 366 documentos com índice $\mathrm{h}=\mathrm{a} 35$ enquanto Suiça publicou 280 documentos e teve um índice $h=63$, África do Sul com 361 documentos teve índice $h=$ 51 , Suécia com 230 documentos teve índice $h=70$, Coréia do Sul com 206 documentos teve índice $h=57$. Esses dados servem para demonstrar como embora alguns países tenham quantitativamente menos documentos publicados, seu impacto medido pelo número de citações é maior.

65 Ver Scimago para todo período analisado aqui: https: / / www.scimagojr.com/countryrank.php?category=3308\&year=2017. 
produção dogmática - geram mais publicações em livros, especialmente em manuais, os pesquisadores de Direito tendem a citá-los mais frequentemente em seus artigos. Curiosamente, os pesquisadores citam artigos de outras áreas para análises empíricas ou desenvolvimento de abordagens multidisciplinares. Esses dois fatores (citações mais frequentes de livros e manuais e de artigos de outras áreas em análises empíricas ou multidisciplinares) podem explicar o baixo impacto da produção em periódicos da própria área do Direito. Dito de outra forma, pesquisadores do Direito aumentam o número de publicações em revistas qualificadas da área, mas citam artigos de áreas correlatas ao Direito, fazendo, na verdade, com que o conhecimento produzido e divulgado em áreas como Sociologia, Ciência Política, Economia e Administração apareçam em maior número quando se pesquisa no Direito.

Para tentar ilustrar um pouco o argumento, realizou-se uma análise exploratória com base em uma busca pelo fator de impacto de revistas qualificadas do Direito que estão indexadas no Scielo. Como buscou-se revistas específicas da área de Direito, excluindo revistas com qualificação superior em Direito editadas por outras áreas, o número de revistas é baixo. Encontrou-se apenas 4 periódicos, entre os quais apenas 2 tem um número de citações das revistas que mais aparecem nesses periódicos. As revistas encontradas são:

Quadro 1 - Periódicos de Direitos indexados na base de Scielo.

\begin{tabular}{|l|l|l|l|l|l|}
\hline $\begin{array}{l}\text { Ano das } \\
\text { publicações } \\
\text { analisadas }\end{array}$ & Nome da Revista & $\begin{array}{l}\text { Edições por } \\
\text { Ano }\end{array}$ & $\begin{array}{l}\text { Artigos } \\
\text { publicados } \\
\text { no período } \\
\text { analisado }\end{array}$ & $\begin{array}{l}\text { Citações } \\
\text { recebidas }\end{array}$ & $\begin{array}{l}\text { Fator de } \\
\text { Impacto }\end{array}$ \\
\hline $2014-2018$ & $\begin{array}{l}\text { Revista de } \\
\text { Investigações } \\
\text { Constitucionais }\end{array}$ & 3 & 137 & 0 & $\begin{array}{l}\text { Não } \\
\text { possui }\end{array}$ \\
\hline $2017-2019$ & Revista Direito e Práxis & 4 & 198 & 0 & $\begin{array}{l}\text { Não } \\
\text { possui }\end{array}$ \\
\hline $2008-2019$ & Revista Direito GV & 3 & 313 & 187 & 0.0481 \\
\hline $2004-2009$ & $\begin{array}{l}\text { SUR- Revista } \\
\text { Internacional de } \\
\text { Direitos Humanos }\end{array}$ & 2 & 93 & 14 & $\begin{array}{l}\text { Não } \\
\text { possui }\end{array}$ \\
\hline
\end{tabular}

Fonte: Elaboração própria a partir dos dados de Scielo.

Quando analisada a rede de revistas que são citadas pelas duas únicas revistas das quais se obteve informações, Direito GV e SUR, temos a seguinte distribuição: 
Quadro 2 - Periódicos citados e número de citações que recebem das revistas de Direito.

\begin{tabular}{|c|c|c|c|}
\hline $\begin{array}{l}\text { Nome das revistas que } \\
\text { aparecem nas mais } \\
\text { citada pela Direito GV }\end{array}$ & $\begin{array}{l}\text { Número de citações que } \\
\text { a revista Recebe }\end{array}$ & $\begin{array}{l}\text { Nome das revistas que } \\
\text { aparecem nas mais } \\
\text { citada pela SUR }\end{array}$ & $\begin{array}{l}\text { Número de citações que } \\
\text { a revista Recebe }\end{array}$ \\
\hline $\begin{array}{l}\text { Revista de Administração } \\
\text { pública }\end{array}$ & 11 & Revista Direito e Práxis & 14 \\
\hline Novos Estudos CEBRAP & 8 & Ciência e Saúde Coletiva & 10 \\
\hline Sequência (Florianópolis) & 8 & $\begin{array}{l}\text { Physis: Revista de Saúde } \\
\text { Coletiva }\end{array}$ & 7 \\
\hline Dados & 8 & Saúde e Sociedade & 7 \\
\hline $\begin{array}{l}\text { Revista de Investigações } \\
\text { Constitucionais }\end{array}$ & 8 & $\begin{array}{l}\text { Lua Nova: Revista de } \\
\text { Cultura e Política }\end{array}$ & 6 \\
\hline
\end{tabular}

Fonte: Elaboração própria a partir dos dados de Scielo.

Para evitar que o resultado ficasse enviesado por referência a apenas uma fonte, observou-se o ranking de revistas de Direito que constam na base Scimago. Apenas 4 revistas aparecem para o ano de 2017. Por ordem de impacto, são elas: Dilemas (Revista de Sociologia), Sur - Revista Internacional de Direitos Humanos, Revista de Direito, Estado e Telecomunicações e Revista de Estudos Constitucionais, Hermenêutica e Teoria do Direito. Com exceção do último periódico, todas as revistas são ligadas a temas importantes para o Direito, mas igualmente transversais a estudos de áreas como Sociologia, Ciência Política e Filosofia.

Esse rápido exercício é mais um indício de que autores que publicam na área jurídica tendem a citar publicações de outras áreas, ainda que próximas ao Direito. Isso somado ao que já foi dito anteriormente sobre a preferência dos pesquisadores da área em citar livros e manuais pode explicar o baixo impacto das revistas jurídicas.

Os dados apresentados nessa seção indicam que, apesar de uma maior institucionalização da área e das melhorias no crescimento quantitativo de pesquisas e no aprimoramento dos pesquisadores de Direito, há ainda espaço para se avançar no impacto da produção da área entre os seus próprios pesquisadores. No caso de pesquisas empíricas, há também grande espaço para se incentivar a capacitação e a produção de pesquisadores da área de Direito. No fundo, como o arcabouço metodológico e diversas fontes de pesquisa têm vindo de áreas relacionadas ao Direito, a área se expande, mas não replica no mesmo ritmo as suas próprias pesquisas. 


\section{CONCLUSÃO}

O texto buscou mostrar empiricamente a institucionalização dos programas de pósgraduação em Direito no Brasil nas duas últimas décadas. Os programas de pós-graduação em Direito cresceram significativamente nos últimos anos, acompanhando, em certa medida, também uma maior expansão dos cursos de graduação ${ }^{66}$ na área no mesmo período. Esse crescimento é observado no expressivo aumento do número de discentes matriculados e titulados especificamente na área de Direito, que possibilitou, por sua vez, a formação de pesquisadores e professores vocacionados a se dedicarem exclusivamente a atividades acadêmicas na área e favoreceu a oferta de temáticas mais multidisciplinares que antes eram enfrentadas em outros domínios, como a Sociologia, a Ciência Política, a Economia ou a Filosofia. Isso significa que a área do Direito passou a ter condições para superar a falta de diferenciação entre operadores do direito e pesquisadores que desde a origem têm caracterizado as atividades acadêmicas da área. Se mantida essa relação de crescimento, a expectativa de melhorias na construção de conhecimento na área do Direito com base nos padrões teóricos e metodológicos vigentes nas demais áreas de Ciências Sociais e Humanidades pode ser concretizada.

No entanto, há ainda alguns desafios acadêmicos a serem superados. Os resultados desta pesquisa revelam que o número de periódicos especializados na área apresentou crescimento nas duas últimas avaliações do Qualis Periódicos, com um aumento no número de revistas nos estratos mais elevados de periódicos propriamente jurídicos, e não de outras áreas. Consequência direta desse fato foi o aumento de publicações na área do Direito. Esse crescimento, todavia, não veio, ao que tudo indica, acompanhado de um maior impacto das pesquisas produzidas na área, o que pode ser explicado por fatores há muito tempo enumerados na literatura sobre a produção a acadêmica no Direito, que apontam para uma baixa formulação teórico-metodológica dos seus pesquisadores e a persistência da tendência à reprodução de

\footnotetext{
${ }^{66}$ Maria Glória Bonneli já destaca sobre a ampliação do mercado privado de cursos de Direito na década de 1990. BONELLI, Maria da Gloria. Docência do direito: fragmentação institucional, gênero e interseccionalidade. Cad. Pesqui., São Paulo, v. 47, n. 163, p. 94-120, mar. 2017. Disponível em http://www.scielo.br/scielo.php?script=sci_arttext\&pid=S0100-15742017000100094\&lng=pt\&nrm=iso. Acesso em: 30 abr. 2020. Segundo os dados do Censo Nacional do Ensino Superior conduzido pelo INEP, em 1998 havia 303 cursos de Direito no Brasil, dando um salto em 2017 para 1207 cursos. Para consultar os dados sobre cursos de graduação ver http://portal.inep.gov.br/web/guest/sinopses-estatisticas-daeducacao-superior .
} 
livros e manuais na produção científica da área, elementos que tornam difícil a replicação de resultados de pesquisa publicados em periódicos.

Se essas hipóteses fazem sentido, pode-se dizer, por fim, que a pesquisa em Direito se estruturou e se institucionalizou fortemente em especial na última década, mas ainda carece de incentivos de formação (sobretudo para o desenvolvimento de pesquisas empíricas) e de desenvolvimento de atividades de pesquisa que contribuam para um maior poder de citação e reprodução de grande parcela da produção intelectual da área, incluindo aquelas divulgadas em periódicos bem ranqueados no sistema Qualis, dentro do próprio campo jurídico. Superar esse desafio é crucial para que a área se robusteça e a pesquisa em Direito possa se tornar não só mais relevante e rigorosa como também empiricamente orientada, multidisciplinar e, consequentemente, mais aderente à realidade que pretende compreender ou influenciar.

\section{REFERÊNCIAS}

ADDOR, Nicolas. A regulação da pesquisa no Brasil e o modelo de avaliação Qualis PeriódicosCAPES. Dissertação (Mestrado em Direito) - Pontifícia Universidade Católica do Paraná. 2018.

ALMEIDA, Elizangela Santos de Almeida. A Formação Stricto Sensu dos Professores dos Cursos de Direito e seus Reflexos no Ensino Jurídico. Dissertação (Mestrado em Educação) Universidade de Uberaba - UNIUBE, Uberaba, MG, 2014. Disponível em: https: / / www.uniube.br/propepe/ppg/educacao/arquivos/2014/listaDissertacoes/DissertacaoElizangela.pdf. Acesso em: 29 abr. 2020.

BALDWIN, Robert; CAVE, Martin; LODGE, Martin. Understanding Regulation. Londres: Oxford University Press, 2011.

BARRADAS BARATA, R. de C. Dez coisas que você deveria saber sobre o Qualis. Revista Brasileira de Pós-Graduação, v. 13, n. 30, 22 dez. 2016.

BONELLI, Maria da Gloria. Docência do direito: fragmentação institucional, gênero e interseccionalidade. Cad. Pesqui., São Paulo, v. 47, n. 163, p. 94-120, mar. 2017. Disponível em http: / / www.scielo.br/scielo.php?script=sci_arttext\&pid=S0100-

$15742017000100094 \&$ ing=pt\&nrm=iso. Acesso em: 30 abr. 2020.

BONELLI, Maria da Gloria. Os sentidos da docência do Direito: discursos, identidades e diferenças. In. Associação Brasileira de Pesquisa em Ciências Sociais. ANPOCS. 2018. Caxambu, MG. Anais... (on-line). Disponível em: https://www.anpocs.com/index.php/papers-40-encontro3/gt-31/gt21-25/11295-os-sentidos-da-docencia-do-direito-discursos-identidades-ediferencas/file

BRASIL. CAPES. Documento orientador de APCN: Área 26: Direito. [s.l], 2019, p. 5. Disponível em: https://www.gov.br/capes/pt-br/centrais-deconteudo/documentos/avaliacao/APCN_DIREITO.pdf . Acesso em: 3 dez. 2021. 
BRASIL. Instituto Nacional de Estudos e Pesquisas Educacionais Anísio Teixeira (Inep). Censo da Educação Superior 2017: notas estatísticas. Brasília, 2018. Disponível em:

https://download.inep.gov.br/educacao_superior/censo_superior/documentos/2018/censo_da_ educacao_superior_2017-notas_estatisticas2.pdf . Acesso em: 30 abr. 2020.

BRASIL. Instituto Nacional de Estudos e Pesquisas Educacionais Anísio Teixeira (Inep). Censo da Educação Superior 2018: notas estatísticas. Brasília, 2019. Disponível em:

https://download.inep.gov.br/educacao_superior/censo_superior/documentos/2019/censo_da_ educacao_superior_2018-notas_estatisticas.pdf . Acesso em: 30 abr. 2020.

CODATO, Adriano; LEITE, Fernando. Autonomização e institucionalização da ciência política brasileira: o papel do sistema Qualis-Capes. Agenda Política, [s.l], v.1, n.1, p. 1-21, 2013. Disponível em:

https://www.agendapolitica.ufscar.br/index.php/agendapolitica/article/view/10 . Acesso em: 30 abr. 2020.

DOTTA, Alexandre Godoy. A estrutura e o financiamento da pós-graduação no Brasil no contexto do desenvolvimento do serviço público de educação. Administrativo \& Constitucional, Belo Horizonte, v. 14, n. 56, p. 229-245, 2014. Disponível em:

http://www.revistaaec.com/index.php/revistaaec/article/view/100 . Acesso em: 30 abr. 2020.

FRAGALE FILHO, Roberto; VERONESE, Alexandre. A pesquisa em direito: diagnóstico e perspectivas. Revista Brasileira de Pós-Graduação, [s.l], v. 1, n. 2, p. 53-70, nov. 2004.

Disponível em: https://rbpg.capes.gov.br/index.php/rbpg/article/view/40 . Acesso em: $30 \mathrm{abr}$. 2020.

GAMEIRO, Ian Pimentel; GUIMARÃES FILHO, Gilberto. O mapa da pós-graduação em Direito no Brasil: uma análise a partir do método da Social Network Analysis. Revista Direito GV, [s.l.], v. 13, n. 3, p. 891-920, jan. 2018. ISSN 2317-6172. Disponível em:

http://bibliotecadigital.fgv.br/ojs/index.php/revdireitogv/article/view/73332. Acesso em: 30 Abr. 2020.

GARTH, Bryant; DEZALAY, Yves. A dolarização do conhecimento técnico-profissional e do Estado: processos transnacionais e questões de legitimação na transformação do Estado, 1960-2000.

Revista Brasileira de Ciências Sociais, São Paulo, v. 15, n. 43, 2000. Disponível em: https://doi.org/10.1590/S0102-69092000000200009 . Acesso em: 30 abr. 2020.

HAMADA, Guilherme Henrique. 0 sistema regulatório de avaliação dos programas stricto sensu no Brasil. Dissertação (Mestrado em Direito) - Pontíficia Universidade Católica do Paraná. 2017.

HOLANDA, Sérgio Buarque de. Raízes do Brasil. 26ª ed. São Paulo: Companhia das Letras, 1995.

JARDIM, Guilherme Duarte. Mapeamento da produção de pesquisa em Direito no Brasil (20032012). Trabalho submetido ao IV Encontro de Pesquisa Empírica em Direito. Ribeirão Preto. 2014.

LEAL, Victor Nunes. Coronelismo, Enxada e Voto. Rio de Janeiro: Forense, 1948. 
LOPES, S. et al. A bibliometria e a avaliação da produção científica: indicadores e ferramentas. Actas dos Congressos Nacionais de Bibliotecários, Arquivistas e Documentalistas, n. 11, 2012. Disponível em: http://www.bad.pt/publicacoes/index.php/congressosbad/issue/view/10. Acesso em: 23 dez. 2021.

MARQUES NETO, Floriano Peixoto de Azevedo. Nova regulação dos serviços públicos. Revista de Direito Administrativo, Rio de Janeiro, v. 228, p. 13-30, abr. 2002. ISSN 2238-5177. Disponível em: http://bibliotecadigital.fgv.br/ojs/index.php/rda/article/view/46521. Acesso em: $30 \mathrm{Abr}$. 2020.

MARTINS, Carlos Benedito; CARVALHO, Inaiá Maria Moreira de. Mestres e doutores em Direito. In: VELLOSO, Jacques (org.). A pós-graduação no Brasil: formação e trabalho de mestres e doutores no país (volume 2). Brasília: Capes, 2003.

NOBRE, Marcos. Apontamentos sobre a pesquisa em direito no Brasil. Cadernos Direito GV. São Paulo, v.1, n. 1, [s.p], 2005. Disponível em: https://bibliotecadigital.fgv.br/dspace/handle/10438/2779?show=full. Acesso em: 22 nov. 2019.

OLIVEIRA, L. 2004. Não fale do Código de Hamurabi! A pesquisa sócio-jurídica na pósgraduação em direito. Rio de Janeiro: Letra Legal. Disponível em: https://edisciplinas.usp.br/pluginfile.php/4213608/mod_resource/content/1/OLIVEIRA\%2C\%2OH amurabi.pdf . Acesso em: 3 dez. 2021.

PLATAFORMA SUCUPIRA. CAPES (site). Disponível em:

https://sucupira.capes.gov.br/sucupira/public/consultas/coleta/programa/listaPrograma.jsf?ac ao $=$ pesquisarArea\&codigoGrandeArea $=60000007 \& d e s c r i c a o G r a n d e A r e a=C I \% 25 C A N C I A S+S O C I A I S+A$ PLICADAS+/. Acesso em: 29 abr. 2021.

PRADO, E. C.; SANTOS, C. M.; PEREIRA JUNIOR, A. M. Pós-graduação stricto sensu em Direito: onde e como se forma o docente dos cursos de graduação. Revista Brasileira de Pós-Graduação, [s.l], v. 12, p. 443-470, 2015. Disponível em:

https://rbpg.capes.gov.br/index.php/rbpg/article/view/814 . Acesso em: 3 dez. 2021.

REGO, Teresa Cristina. Produtivismo, pesquisa e comunicação científica: entre o veneno e o remédio. Educ. Pesqui., São Paulo, v. 40, n. 2, p. 325-346, jun. 2014. Disponível em: http: / /www.scielo.br/scielo.php?script=sci_arttext\&pid=S151797022014000200003\&lng=pt\&nrm=iso . Acesso em: 30 abr. 2020.

SCHWARTZMAN. S. 1990. Tradição e Modernidade da Universidade Brasileira. São Paulo, 1990, Mimeo.

SCIELO. (site). Disponível em:

http://statbiblio.scielo.org/stat_biblio/index.php?\&state=03\&lang=en\&country=scl. Acesso em: 3 dez. 2021.

SINOPSE Estatística da Educação Superior 2017. Brasília: INEP, 2018. Disponível em http://portal.inep.gov.br/basica-censo-escolar-sinopse-sinopse . Acesso em 30 abr. 2020. 
UNGER, Roberto Mangabeira. Uma nova faculdade de direito no Brasil. Revista de Direito Administrativo, Rio de Janeiro, v. 243, p. 113-131, 2006. Disponível em:

https: / / bibliotecadigital.fgv.br/ojs/index.php/rda/article/view/42553 . Acesso em: 3 dez. 2021.

VARELLA, Marcelo. Quem influencia a pós-Graduação em Direito no Brasil? Uma análise empírica da nucleação acadêmica. Revista de Direito Brasileira. Florianópolis, v. 12, p. 111-127, 2015. Disponível em: https://www.indexlaw.org/index.php/rdb/article/view/2817/2669 . Acesso em: 3 dez. 2021.

VERHINE, Robert E. Avaliação e regulação da educação superior: uma análise a partir dos primeiros 10 anos do SINAES. Avaliação (Campinas), Sorocaba, v. 20, n. 3, p. 603-619, nov. 2015. Disponível em: https://doi.org/10.1590/S1414-40772015000300003. Acesso em: 30 abr. 2020.

XAVIER, José Roberto. A Pesquisa Empírica e o Direito. Rio de Janeiro: Autografia, 2018.

WOHNRATH, Vinicius. Educação e elites jurídicas: espaços de formação doutoral em direito no Brasil contemporâneo. In: DE HOLANDA, Ana Paula A.; GRDILHO, Heron J. de S.; SILVA, Maria dos Remédios F.; MARTINI, Sandra R.; CARDIN, Valéria S. G (Coords.). Filosofia do direito hoje: temas atuais. 1 ed. Zaragoza: Prensas de la Universidad de Zaragoza, 2019, p. 365 - 388.

\section{ANEXO}

\section{Anexo 1}

Quadro 1 - Áreas e concentração dos programas de pós-graduação stricto sensu na área do Direito

\section{1}

DIREITO CIVIL, PENAL, DO ESTADO, ECONÔMICO E FINANCEIRO, INTERNACIONAL, PENAL, PROCESSUAL, FILOSOFIA E TEORIA DO DIREITO, DIREITOS HUMANOS, DIREITO DO TRABALHO

1972

TEORIA DO ESTADO E DIREITO CONSTITUCIONAL

TEORIA E DOGMÁTICA DO DIREITO

1973

EFETIVIDADE DO DIREITO

1974

DIREITO, ESTADO E SOCIEDADE, TEORIA DO DIREITO, DIREITO INTERNACIONAL E

SUSTENTABILIDADE

1975

DIREITO, ESTADO E CONSTITUIÇÃO

DIREITOS FUNDAMENTAIS E ACESSO A JUSTICA 
ISSN 1981-3694

(DOI): $10.5902 / 1981369447110$

1977

ORDEM JURÍDICA CONSTITUCIONAL

1978

DIREITO E JUSTICA

DIREITO NEGOCIAL

DIREITO, ESTADO E CIDADANIA

1982

DIREITO DAS RELAÇÕES SOCIAIS, DIREITOS HUMANOS E DEMOCRACIA, DIREITO DO ESTADO

1984

DIREITOS HUMANOS

1985

FUNDAMENTOS DA EXPERIÊNCIA JURÍDICA

1988

FUNDAMENTOS CONSTITUCIONAIS DO DIREITO PÚBLICO E PRIVADO E TEORIA GERAL DA

JURISDIÇÃO E PROCESSO

1990

SISTEMAS NORMATIVOS E FUNDAMENTOS DA CIDADANIA

1991

CIDADNIA, PENSAMENTO E RELAÇÕES PRIVADAS

1993

DIREITOS FUNDAMENTAIS COLETIVOS E DIFUSOS

1994

DIREITO PÚBLICO E EVOLUÇÃO SOCIAL

1995

CONSTITUCIONALISMO, TRANSNACIONALIDADE E PRODUÇÃO DO DIREITO

DIREITO ECONÔMICO E DESENVOLVIMENTO

1996

DIREITOS HUMANOS E DESENVOLVIMENTO

1997

DIREITO PROCESSUAL, PÚBLICO, PRIVADO E TEORIA DO DIREITO

DIREITO PÚBLICO E DIREITO EMPRESARIAL

RELAÇÕES ECONÔMICAS E SOCIAIS

SISTEMA PENAL E VIOLÊNCIA

1998

DIREITOS SOCIAIS E POLITICAS PÚBLICAS

SISTEMA CONSTITUCIONAL E GARANTIA DE DIREITOS

1999 
ISSN 1981-3694

(DOI): $10.5902 / 1981369447110$

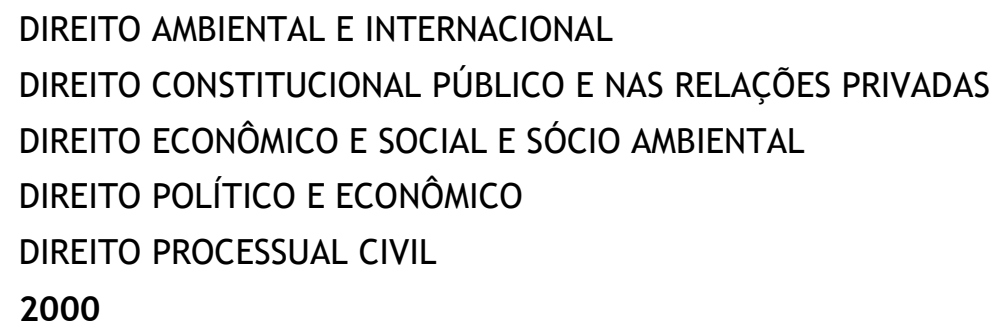


ISSN 1981-3694

(DOI): $10.5902 / 1981369447110$

A EXPANSÃO DA PÓS-GRADUAÇÃO EM DIREITO NO BRASIL (19982017): AVANÇO QUANTITATIVO E PERSISTÊNCIAS METODOLÓGICAS

DIREITOS E GARANTIAS FUNDAMENTAIS

TEORIAS JURÍDICAS CONTEMPORÂNEAS

2010

CONSTITUCIONALISMO E DEMOCRACIA

DIREITOS HUMANOS E DIREITO AMBIENTAL

INSTITUICOES SOCIAIS, DIREITO E DEMOCRACIA

2011

CONSTITUCIONALIZAÇÃO DO DIREITO

DIREITO AMBIENTAL E DESENVOLVIMENTO SUSTENTÁVEL

DIREITO CONSTITUCIONAL, ADMINISTRAÇÃO, TEORIA JURÍDICA

DIREITOS HUMANOS

2012

CONCRETIZAÇÃO DOS DIREITOS SOCIAIS, DIFUSOS E COLETIVOS

DIREITO E INSTITUIÇÕES DO SISTEMA DE JUSTIÇA

DIREITO, POLÍTICAS PÚBLICAS E DESENVOLVIMENTO REGIONAL

DIREITOS COLETIVOS E CIDADANIA

DIREITOS FUNDAMENTAIS

DIREITOS HUMANOS

ESTADO, SOCIEDADE E POLÍTICAS PÚBLICAS

JUSTIÇA, EMPRESA E SUSTENTABILIDADE

JUSTIÇA, PROCESSOS E DIREITOS HUMANOS

2013

DIMENSÕES MATERIAIS E EFICACIAIS DOS DIREITOS FUNDAMENTAIS

DIREITO E EMPREENDIMENTO

DIREITO E INOVAÇÃO

DIREITO, DEMOCRACIA E SUSTENTABILIDADE

DIREITOS EMERGENTES NA SOCIEDADE GLOBAL

DIREITOS HUMANOS

2014

CIDADANIAS, ESTADO E INTERNACIONALIZAÇÃO DAS RELAÇÕES JURÍDICAS

DESENVOLVIMENTO NO ESTADO DEMOCRÁTICO DE DIREITO

DIREITO DA REGULAÇÃO

DIREITO E DESENVOLVIMENTO SUSTENTÁVEL

DIREITO E JUSTIÇA SOCIAL

DIREITO E SOCIEDADE

NOVOS PARADIGMAS DO DIREITO

REALIZAÇÃO JURÍDICO-POLÍTICA DOS DIREITOS FUNDAMENTAIS

SOLUÇÕES ALTERNATIVAS DE CONTROVÉRSIAS JUDICIAIS

2015 


\author{
DIREITO E GESTÃO DE CONFLITOS \\ DIREITO PÚBLICO E DIREITO EMPRESARIAL \\ DIREITOS DA CIDADANIA \\ HISTÓRIA DO PENSAMENTO JURÍDICO \\ 2016
}

DIREITO DA SAÚDE, DIMENSÕES INDIVIDUAIS E COLETIVAS

DIREITO DAS RELAÇÕES SOCIAIS E TRABALHISTAS

DIREITO, ESTADO E SOCIEDADE, TEORIA DO DIREITO, DIREITO INTERNACIONAL E

SUSTENTABILIDADE

DIREITOS HUMANOS

FUNDAMENTOS E EFETIVIDADE DO DIREITO

PODER, ESTADO E JURISDIÇÃO

RELAÇÕES PRIVADAS, SOCIEDADE E DESENVOLVIMENTO

TUTELA A EFETIVAÇÃO DE DIREITOS INDISPONÍVEIS

2017

CONSTITUCIONALISMO, TRANSNACIONALIDADE E PRODUÇÃO DO DIREITO

DIREITO DA ADMINISTRAÇÃO E DAS POLÍTICAS PÚBLICAS

DIREITO TRIBUTÁRIO INTERNACIONAL E DESENVOLVIMENTO

DIREITO, ACESSO A JUSTIÇA E AO DESENVOLVIMENTO

DIREITOS HUMANOS E SOCIEDADE

DIREITOS SOCIAIS

NOVOS DIREITOS, NOVOS SUJEITOS

Recebido em: 11.06.2020 / Revisões requeridas em: 08.10.2021 / Aprovado em: 25.11.2021 / Publicado em: 30.12.2021

\title{
COMO FAZER REFERÊNCIA AO ARTIGO (ABNT):
}

ROCHA, Décio Vieira da; LEAL, Fernando; RIBEIRO, Leandro Molhano. A expansão da pós-graduação em Direito no Brasil (1998-2017): avanço quantitativo e persistências metodológicas. Revista Eletrônica do Curso de Direito da UFSM, Santa Maria, RS, v. 16, n. 2, e47110, maio/ago. 2021. ISSN 1981-3694. DOI:

http://dx.doi.org/10.5902/1981369447110. Disponível em:

https://periodicos.ufsm.br/revistadireito/article/view/47110 Acesso em: dia mês. ano.

Direitos autorais 2021 Revista Eletrônica do Curso de Direito da UFSM

Editores responsáveis: Rafael Santos de Oliveira e Angela Araujo da Silveira Espindola

\section{(1) $\odot \odot$}

Esta obra está licenciada com uma Licença Creative Commons Atribuição-NãoComercial-SemDerivações 4.0 Internacional.

\section{SOBRE OS AUTORES}

\section{DÉCIO VIEIRA DA ROCHA CORREIO}

Graduado em Ciências Sociais e mestre em Sociologia Política pela UENF. Doutor em Ciência Política pelo Instituto de Estudos Sociais e Políticos (IESP-UERJ). Tem interesse de pesquisa em partidos e eleições, teorias da regulação, comportamento político e processos institucionais. Pesquisador no Centro de Pesquisa em Direito e Economia (CPDE) FGV Direito Rio. 
ISSN 1981-3694

(DOI): $10.5902 / 1981369447110$

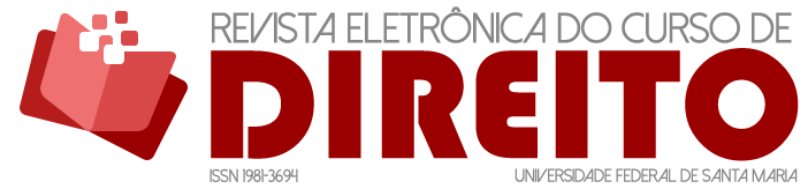

A EXPANSÃO DA PÓS-GRADUAÇÃO EM DIREITO NO BRASIL (19982017): AVANÇO QUANTITATIVO E PERSISTÊNCIAS METODOLÓGICAS

DÉCIO VIEIRA DA ROCHA

FERNANDO LEAL

LEANDRO MOLHANO RIBEIRO

\section{FERNANDO LEAL CORREIO}

Doutor em Direito pela Christian-Albrechts-Universität zu Kiel e Professor na graduação em Direito da Escola de Direito do Rio de Janeiro da Fundação Getúlio Vargas (FGV DIREITO RIO) e do Programa de Pós-Graduação (mestrado e Doutorado) em Direito da Regulação na mesma instituição.

\section{LEANDRO MOLHANO RIBEIRO}

Doutor em Ciência Política pelo Instituto Universitário de Pesquisas do Rio de Janeiro (luperj), Mestre em Ciência Política pelo luperj e Graduado em Ciências Sociais pela Universidade Federal de Minas Gerais (UFMG). Professor na Graduação em Direito da Escola de Direito do Rio de Janeiro da Fundação Getúlio Vargas (FGV DIREITO RIO) e do Programa de PósGraduação (mestrado e Doutorado) em Direito da Regulação na mesma instituição. 